\title{
The ALTIUS mission
}

\section{Didier Fussen, Emmanuel Dekemper, Quentin Errera, Ghislain Franssens, Nina Mateshvili, Didier Pieroux, and Filip Vanhellemont}

Royal Belgian Institute for Space Aeronomy, 3, avenue Circulaire, B1180 Brussels, BELGIUM

Correspondence to: Didier Fussen (Didier.Fussen@aeronomie.be)

\begin{abstract}
.
This article outlines the objectives, concept and expected performance of the ALTIUS (Atmospheric Limb Tracker for the Investigation of the Upcoming Stratosphere) mission in view of the continuation of earth limb measurements for atmospheric science. This type of measurement became rare with the failure of the European ENVISAT mission in 2012 and the number will further decrease when several Canadian, Swedish and US limb missions will terminate within the next few years. The project is presented in the frame of a small mission initiative based on a micro-satellite platform of the PROBA (Project for On-Board Autonomy) class, with a high agility allowing for atmospheric limb observations in different remote sensing geometries from a low earth orbit. The instrument consists of three independent spectral imagers covering the UV-Vis-NIR ranges.

Recently, the ALTIUS mission has been declared as an element compliant to the ESA Earth Watch programme.

The paper identifies the general scientific context of the project and derives the mission, instrument and scientific products requirements. The general design of the payload and platform systems is discussed. The preliminary data processing chain is presented, from telemetry data to retrieved geophysical profiles, with a complementary data assimilation level. A preliminary assessment of the mission performance is discussed with focus on ozone profile retrievals, which are the main objective of the mission.
\end{abstract}

\section{Introduction}

\subsection{Evolution of the Earth's upper atmosphere during the 21st century}

It is now accepted that the global and polar depletions of the ozone layer can be attributed to the presence of halogen compounds released by anthropogenic emissions. The Montreal protocol has caused a decrease in the stratospheric halogen load and a slowing of ozone decline is expected to be the natural precursor of a complete ozone recovery towards 2050 . There is presently some experimental evidence that the global mean ozone total column is no longer decreasing with respect to the 1998-2001 period. Also, the ozone stratospheric distribution has been relatively constant during the last decade although both dynamical and chemical processes may contribute to decadal changes in the lower stratosphere. Clearly, the monitoring of ozone stratospheric abundances is of crucial importance in assessing the milestones of a clear recovery process on a global scale (Stocker, 2013). 
Atmos. Meas. Tech. Discuss., doi:10.5194/amt-2016-213, 2016

Manuscript under review for journal Atmos. Meas. Tech.

Published: 3 August 2016

(c) Author(s) 2016. CC-BY 3.0 License.

(c) (i)

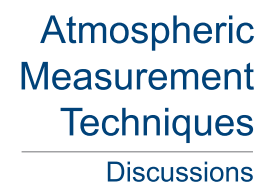

Among important trace gases, methane is very important for its impact on climate through a large radiative forcing effect and the production of stratospheric water vapour. The global increase of about $0.7 \mathrm{ppm}$ in $1800 \mathrm{AD}$ to $1.8 \mathrm{ppm}$ nowadays is difficult to interpret because of the diversity of the sources: wetlands, enteric fermentation, fires and rice agriculture. The odd hydrogen family, HOx, contains all active species, i.e. radicals that are involved in catalytic cycles that destroy Ox. The HOx radicals are derived primarily from the oxidation of water vapour in the stratosphere and it is therefore essential to understand and to monitor the intrusion of water vapour into the stratosphere, especially in the region of the tropical tropopause (Hegglin, 2013). Similarly, the NOx family is known to play an essential catalytic role in ozone destruction with a strong diurnal cycle that requires day- and night-time measurements for a complete understanding.

Much remains to be learned about polar stratospheric clouds (PSC) and we do not know enough about particle sizes, crystal morphology and even composition. The same uncertainty holds for polar mesospheric clouds (PMC), similar in appearance to thin cirrus clouds, but located at a much higher altitude, from 80 to $87 \mathrm{~km}$ near the mesopause. PMCs only occur at high latitudes during summer (a few weeks before and after the solstice), when the mesosphere becomes extremely cold (with temperatures as low as 100 Kelvin) (Deland, 2007). Their increasing occurrence may be a sign of climate change in the upper atmosphere.

On the other side, the scientific community is requiring an urgent response to the present lack of atmospheric remote sounders (see Figure 1 ) with a high vertical resolution. Since the end of ENVISAT in 2012, some aging limb missions/instruments are still operating (ODIN/OSIRIS (Llewellyn, 2004), AURA/MLS (Froidevaux, 2008), ACE/FTS-MAESTRO (Dupuy, 2009), OMPS-NPP/LS (Moy, 2016)) but they are all beyond their nominal lifetime. In the near future, ISS/SAGE-III (2016) and JPSS2/OMPS-LP (2022) are the only approved missions so far and there is no guarantee concerning a possible overlap between them.

This article presents the concepts of a mission called ALTIUS (Atmospheric Limb Tracking for the Investigation of the Upcoming Stratosphere) that was successfully proposed by the Belgian Institute for Space Aeronomy (BISA) to the Belgian Scientific Policy Office (BELSPO) and that has been recently approved by the European Space Agency (ESA) as an element of the ESA Earth Watch programme. The general description reads as "ALTIUS aims at the development, launch, in-orbit operation, data processing, data archiving and products distribution of a limb sounder mission based on a small satellite. Its main objective is the monitoring of the 3-D distribution and evolution of stratospheric ozone at high vertical resolution. The versatile instrument, which will image the Earth's limb in the near UV, Visible and Near Infrared spectral regions, in combination with the agility provided by the spacecraft platform can allow measurements of concentration profiles of other species as well as of aerosol extinction vertical profiles."

The present paper gives an overview of the objectives, concept and expected performances of the ALTIUS mission as proposed by BISA, on its way to a preliminary design review (PDR), expected at the end of 2017. 
Atmos. Meas. Tech. Discuss., doi:10.5194/amt-2016-213, 2016

Manuscript under review for journal Atmos. Meas. Tech.

Published: 3 August 2016

(c) Author(s) 2016. CC-BY 3.0 License.

(c) (i)

$\begin{array}{r}\text { Atmospheric } \\ \text { Measurement } \\ \text { Techniques } \\ \hline \text { Discussions }\end{array}$

\subsection{Scientific objectives of the ALTIUS mission}

In view of the need for atmospheric composition measurements on a global scale and with a high vertical resolution, it is useful to summarize the mission objectives in a series of scientific requirements (SR) and to group them into subsets respectively identified as of "mandatory", "important" and "relevant" weight.

\section{$5 \quad$ 1.2.1 Mandatory scientific requirements}

SR1 Global and long-term vertically resolved ozone data sets of observations in the stratosphere are urgently required to assess model behaviour and test model predictions, particularly in the upper troposphere lower stratosphere (UTLS) domain, in polar regions and in the Southern Hemisphere. Today, the ozone recovery, which is probable but not yet confirmed, is still an open question.

SR2 The measurement of ozone profiles in the middle stratosphere at $5 \%$ accuracy level has to be continued to reinforce the significance of the existing climatologies. A special effort is needed in the UTLS region to improve the determination of trends and to detect increase in upwelling, a predicted climate change effect.

SR3 The spread of existing ozone profile data in ozone hole conditions is not satisfactory. Limb observations should allow determining spatial concentration gradients across and along the vortex while detecting PSC's for data screening and correlative analyses, during all seasons (including polar night).

SR4 ALTIUS should also provide highly resolved vertical profiles of mesospheric $\mathrm{O}_{3}$, a key species to understand the atmospheric coupling, not yet well understood, between the lower atmosphere and the upper stratosphere, mesosphere and lower thermosphere.

\subsubsection{Important scientific requirements}

SR5 ALTIUS will provide highly resolved vertical profiles of $\mathrm{NO}_{2}$ from the UTLS to the upper stratosphere, mesosphere and lower thermosphere at different local times. It will provide intercomparison of $\mathrm{NO}_{2}$ and $\mathrm{O}_{3}$ abundances. It will also focus on the dynamics and the chemistry of strong $\mathrm{NO}_{2}$ enhancements in the upper stratosphere-mesosphere.

SR6 The mission will provide global vertical profiles of $\mathrm{H}_{2} \mathrm{O}$ and $\mathrm{CH}_{4}$, with a special focus, for water vapor, on the tropical tape recorder and vortex dehydration. A major objective for these interrelated species will be the measurement of their trends in the lower stratosphere.

SR7 ALTIUS will provide extinction profiles and particle size distributions of stratospheric aerosol by observing vertical extinction profiles in the UV-Vis-NIR wavelength ranges. Depending on the volcanic state of the atmosphere, it will assess the relaxation times of the volcanic contribution or the evolution of the background non-volcanic contribution.

SR8 It is important to measure the frequency of PSC occurrences inside the polar vortex and their temperature dependence. 
Atmos. Meas. Tech. Discuss., doi:10.5194/amt-2016-213, 2016

Manuscript under review for journal Atmos. Meas. Tech.

Published: 3 August 2016

(c) Author(s) 2016. CC-BY 3.0 License.

(c) (i)

$\begin{array}{r}\text { Atmospheric } \\ \text { Measurement } \\ \text { Techniques } \\ \hline \text { Discussions }\end{array}$

\subsubsection{Relevant scientific requirements}

SR9 ALTIUS will measure the trend and the phase in the occurrence of PMC's as well as their median altitude and their horizontal extent, in both hemispheres, around the summer solstice.

SR10 ALTIUS will measure $\mathrm{OClO}, \mathrm{BrO}$ and $\mathrm{NO}_{3}$, that are important minor trace gases involved in the stratospheric chemistry.

5 SR11 In solar occultation mode, by making use of imaging techniques at large S/N ratio, ALTIUS will retrieve density and temperature profiles up to the mesosphere, from refraction angle measurements.

SR12 Horizontal concentration gradients of relevant trace gases will be observed in "along track" and "across track" geometries, allowing for tomographic retrievals during successive revolutions.

\subsection{ALTIUS scientific product and mission requirements}

In Table 1, we report the target scientific product requirements related to the abovementioned scientific objectives. The baseline assumption for ALTIUS supposes a limb sounder onboard a micro-satellite platform (a PROBA class carrier was pre-selected for its agility and pointing performance). This choice ensures a global coverage (including polar regions) if launched in a heliosynchronous low earth orbit (LEO), and the capability to achieve the highest vertical resolution. As a threshold requirement for the use of ALTIUS data in present assimilation models, the global coverage should be sampled on a grid finer than 5-10 degrees in latitude and 10 degrees in longitude.

Global coverage and high vertical resolution can be achieved by combining several observation modes based on the interaction of the light emitted by a celestial body and the atmosphere, such as the limb-scattered solar light, solar (and lunar) occultations, stellar (and planetary) occultations. Indeed, bright limb measurements offer a large sampling on the day side of the orbit, while occultations add a number of measurement points on the night side.

This multimode capacity requires some agility, autonomy and stability from the satellite, which is precisely what has been demonstrated by the PROBA platform. A further constraint is that ALTIUS must be the only payload with pointing requirements onboard. Limb measurements (not based on atmospheric emissions) are very sensitive to the tangent altitude registration of the line-of-sight(LOS), i.e. the closest point to the local geoid, especially where the concentration profiles show large vertical gradients. Previous limb-scatter instruments have experienced serious tangent height misregistration issues (SCIAMACHY, OSIRIS, OMPS). Occultations also need to keep the light source in the field-of-view (FOV). The original approach proposed for ALTIUS is to use an imaging system with a FOV matching the apparent size of the bright limb (0-100km). With this method, in-flight calibration methods are more easily implemented to solve the pointing issue. The entire atmosphere is probed at once, which is an advantage compared to scanning systems which take tens of seconds to complete the scan (and lose in along-track resolution). In addition, inertial pointing to the occulted celestial bodies is done without the need for complex light source tracking systems (as it was the case for GOMOS on ENVISAT). 
Atmos. Meas. Tech. Discuss., doi:10.5194/amt-2016-213, 2016

Manuscript under review for journal Atmos. Meas. Tech.

Published: 3 August 2016

(c) Author(s) 2016. CC-BY 3.0 License.

(c) (i)

$\begin{array}{r}\text { Atmospheric } \\ \text { Measurement } \\ \text { Techniques } \\ \hline \text { Discussions }\end{array}$

\section{Instrument requirements and operation concepts}

\subsection{Instrument concept and requirements}

In order to solve the tangent height misregistration problem, ALTIUS is designed as a limb imager for which the field-of-view can be calibrated by different techniques. Assuming a rectangular FOV, the atmospheric limb shall be imaged between 0 and $5100 \mathrm{~km}$ (about $34 \times 34 \mathrm{mrad}$ ) although stellar and planetary occultations can be performed with a smaller FOV of $3.4 \times 3.4$ mrad. The pixel FOV will be less than or equal to $0.2 \mathrm{mrad}$ allowing for a vertical sampling better than $0.6 \mathrm{~km}$. The overall instrument Modulation Transfer Function (MTF) at 2.5 cycles/mrad will be greater than $20 \%$ and, for stellar occultations, more than $20 \%$ of the energy will be concentrated in a single pixel.

Clearly, limb imaging imposes stringent pointing requirements on the system. If we consider a Cartesian Boresight Reference

10 Frame (BRF) centered at the detector with the $\mathrm{Z}$ axis pointing to the limb horizon, the $\mathrm{X}$ and $\mathrm{Y}$ axis respectively perpendicular and parallel to the horizon, we can define angular uncertainties related to the rotations $\mathrm{R}_{Z}, \mathrm{R}_{X}$ and $\mathrm{R}_{Y}$ around these axes.The corresponding requirements are reported in Table 2 for the Mean Performance Error (MPE), Mean Knowledge Error (MKE), Relative Performance Error (RPE), Relative Knowledge Error (RKE), Performance Drift Error (PDE) and Knowledge Drift Error (KDE) (see Ott (2011) for an exact definition of these error terms).

ALTIUS may be described as an imaging spectrometer of moderate spectral resolution. The instrument will be a tuneable spectral imager capable of observing the atmospheric limb in the UV (250-400 nm), VIS (420-800 nm) and NIR (800-1800 nm) domains, with a spectral width (depending quadratically on wavelength) always better than 10 nanometers for VIS and NIR and better than $2.5 \mathrm{~nm}$ for UV. A distinct spectral tuneable element will filter observations in each of these three wavelength ranges.

In general, the instrument will operate at different measurement rates corresponding to the different observation geometries. For limb scattering observations, the along track sampling rate is consistent with the effective optical length along the line-ofsight (about $500 \mathrm{~km}$ ). It is important to notice that a limb pointing instrument is unable to achieve a very large swath like a nadir looking sensor due to the Earth curvature. In Table 2, we report the typical number of images (spectral snapshots) and observations (minimum ensemble of images at different wavelengths to retrieve the spectral absorber profiles).

In Table 3, we identify the useful spectral windows to measure the concentration profiles of the main target gases together with the required maximum spectral width, minimum SNR and maximum acceptable pointing error. In limb mode, a typical set of 10 wavelengths per channel will be recorded nominally in ten seconds to obtain sufficient spectral information content with a maximal geographical resolution. However, it will be possible to increase the measurement time up to 50 seconds (or even 100 seconds in the worst case) to improve the S/N ratio. Pixel binning (up to the full detector row) will also be made possible for the same purpose at the price of a reduced horizontal resolution. 
Atmos. Meas. Tech. Discuss., doi:10.5194/amt-2016-213, 2016

Manuscript under review for journal Atmos. Meas. Tech.

Published: 3 August 2016

(c) Author(s) 2016. CC-BY 3.0 License.

\author{
Atmospheric \\ Measurement \\ Techniques \\ Discussions
}

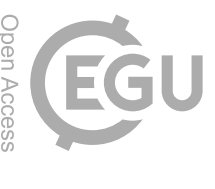

\subsection{Instrument design}

If the goal was to take spectral pictures at fixed wavelengths, a filter wheel could have been used. But then the wavelengths would be frozen, with a supplementary risk of mechanical failure in space environment. To overcome these issues, ALTIUS will use a tunable approach based on:

- Acousto-optical tunable filters (AOTF) for the VIS and IR channels.

- Fabry-Pérot interferometers (FPI) for the UV channel.

AOTFs are small birefringent crystals (typically a few cubic centimetres) serving as interaction medium between the incoming light and an acoustic wave propagating in the crystal (Dekemper, 2012; Chang, 1974; Xu, 1992). By carefully selecting the wave frequency, the acousto-optic interaction turns induces a Bragg diffraction regime that deflects light with a specific wavelength away from its incident direction (by a few degrees). The diverted beam can then be collected by an off-axis optical detector. Used inside an imaging system, such a device offers many advantages:it is small and lightweight, contains no moving parts, it consumes only 1 to 3 watts and can be tuned to the required wavelength in a few milliseconds. An AOTF works over a broad spectral range (hundreds of nanometres) with a variable bandwidth (quadratic in wavelength) that can be optimized by design (from sub-nm to $10 \mathrm{~nm}$ ).

As AOTF crystals in the UV region are not yet mature enough to be considered as a suitable technology for space application, the filter element for that region will consist of a cascade of Fabry-Pérot interferometers.

ALTIUS benefits from a relatively simple optical design. The three spectral channels share the same idea: an aperture collects the (ir)radiance of the scene which is then reflected by a number of mirrors to form an image onto a detector array. Located approximately half-way between the aperture and the detector, a tuneable spectral filter captures a fraction of the light spectrum while the rest of the incident beam is blocked by the combined action of a beam stop and cross-oriented polarizers (AOTF), or by the filter itself (Fabry-Pérot).

Each channel is made of reflective optics and contains the same set of functional modules:

- A mechanical structure

- A front-end optics group (FEO), to guide the incoming light towards the spectral element

- A spectral filter (AOTF module or FPI assembly)

- A back-end optics group (BEO) to focus the filtered image on the detector

- A detector with optional cooling capacity

- A driving and read-out electronic board

At the detector level, a 512x512 CMOS image sensor is proposed, suitable for atmospheric absorption measurements as a hyper-spectral application in the UV and visible wavelength ranges. It has a programmable or automatic high dynamic range: 
Atmos. Meas. Tech. Discuss., doi:10.5194/amt-2016-213, 2016

Manuscript under review for journal Atmos. Meas. Tech.

Published: 3 August 2016

(c) Author(s) 2016. CC-BY 3.0 License.

(c) (i)

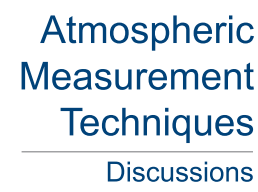

two full well factors are foreseen with a ratio of 15 and a linearly or exponentially varying row integration time along the atmospheric radiance gradient, capable of at least 10 frames per second, and a wide operational temperature domain. For the NIR detector, the required SNR imposes a $190 \mathrm{~K}$ working temperature which will be obtained by using a Stirling cooler. Such a device is capable of significantly reducing the chip operating temperature at the expense of a power consumption of about 5

$\mathrm{W}$ and a limited lifetime that will have to be taken into account in the mission scenario.

An extended set of on-ground calibrations is foreseen to fully characterize the sensor. Instrument performance will be checked at an accuracy level compatible with the sensor requirements (typically $1 / 10$ pixel for LOS and pointing, 1-3 \% for radiometric quantities, 1/10 of spectral bandwidth for wavelength). In particular, the following characteristics will be calibrated:

- LOS calibration per channel.

- LOS and pixel mapping for FOV, IFOV and distortion.

- Temperature dependence of pixel mapping.

- MTF and point spread function.

- Radiometric response: PRNU, SNR, pixel non-linearity and dynamic range.

- Straylight.

- Spectral response: wavelength calibration and temperature dependence, bandwidth and out-of-band rejection.

So far, the ALTIUS sensor design has been performed through many technical studies to demonstrate its feasibility and its compliance to the payload requirements. All these study phases have been thoroughly reviewed by several technical committees. No showstoppers were found whereas missing studies or optimizations have been identified: a detailed description of the payload/platform interface, a global optimization of the UV channel, the detector layout, the payload electrical design, a consolidated thermal analysis focused on the assessment of the thermo-elastic effects (and their impact on the pointing requirements) and a comprehensive straylight analysis. All these missing technical studies will have to be conducted before the Preliminary Design Review (PDR) presently foreseen at the end of 2017 and will support several publications about a detailed and consolidated description of the sensor.

\subsection{Platform, orbit and operations}

\subsubsection{Platform}

The payload has been designed to fit in an evolved PROBA platform design, as shown in Fig. 2 (internal view) and Fig. 3 (external view) below. The platform generic design has been modified in order to implement a propulsion system, to provide the necessary accommodation volume for the instrument as well as sufficient power to sustain the mission, and to remain within volume constraints for a set of realistic launchers compatible with the ALTIUS mission. 
Atmos. Meas. Tech. Discuss., doi:10.5194/amt-2016-213, 2016

Manuscript under review for journal Atmos. Meas. Tech.

Published: 3 August 2016

(c) Author(s) 2016. CC-BY 3.0 License.

(c) (i)

\author{
Atmospheric \\ Measurement \\ Techniques \\ Discussions
}

\subsubsection{Orbit}

Heliosynchronicity is a standard requirement for a limb-scattering instrument as air masses are sounded at a constant local solar time, while it makes the radiative transfer problem of the limb-scattered light more easily addressed by narrowing the range of solar angles to a small subset (drift of the orbital local ascending node will be limited to 0.5 hours over the mission lifetime).

5 A revisit time of about 3 days was selected (similar to ENVISAT) with some loose requirements on the exact overlapping of the S/C ground tracks. For a low earth circular orbit (LEO) at an altitude of $680 \mathrm{~km}$, this allows for an interesting trade-off between a short revisit time and a dense geographical sampling grid (about $800 \mathrm{~km}$ between successive tracks at equator) that matches the typical horizontal resolution of data assimilation models.

\subsubsection{Baseline operations}

During $90 \%$ of the mission time, ALTIUS will be operated according to a so-called "baseline" scenario depicted in Fig. 4:

1. On the dayside (bright limb), it observes scattered solar radiation in the backward direction with respect to the velocity vector

2. When approaching the terminator, a spacecraft manoeuvre brings the Sun into the FOV to observe a sunset occultation in inertial pointing mode

3. On the nightside (dark limb), 5 to 10 bodies (stars and planets) are selected and rallied to observe their occultation

4. At the terminator again, ALTIUS observes a sunrise occultation

5. Back to step 1, for a new cycle of observations.

All system resources (energy, thermal budget, telemetry,..) have been optimized from this scenario. However, $10 \%$ of the mission scenario is spare for less regular activities, including instrument calibration campaigns. The sequence of night objects (stars, planets and the Moon) selected for candidate observations was optimized with respect to the number of necessary satellite manoeuvres. In Fig. 5, we report the ensemble of successive observations for one satellite revolution in the baseline scenario, with successive sunrise occultation, limb scattering observations in dayside, sunset and, in the nightside, stellar, planetary and lunar occultations. A full day of ALTIUS observations is plotted in Fig. 6, where the geolocations of observations are progressing westward by about 24 degrees between two successive revolutions. The simulation was performed for a quasicircular (eccentricity $=1.0510^{-3}$ degree) orbit with a semi-major axis of $7050 \mathrm{~km}$ and an inclination of $98.07^{\circ}$ degrees. Fig. 7 and 8 respectively represent the seasonal evolution of bright limb and solar occultation geolocations, the latter ones being confined to rather high latitudes as a consequence of the almost polar orbit inclination. On the other hand, lunar occultations in dark limb are also possible and allow for tropical observations (see Fig. 9). Finally, we also report the geolocations of brightest star and planet occultations in Figs. 10 and 11. 
Atmos. Meas. Tech. Discuss., doi:10.5194/amt-2016-213, 2016

Manuscript under review for journal Atmos. Meas. Tech.

Published: 3 August 2016

(c) Author(s) 2016. CC-BY 3.0 License.

(c) (i)

\author{
Atmospheric \\ Measurement \\ Techniques \\ Discussions
}

\subsubsection{Special observation modes}

As a serendipitous mode of observation, it shall also be possible to perform tomography of a species 3D distribution field in the low latitude regions. Due to the remarkable (and fortuitous) fact that the azimuthal angular distance to the side horizon is close to the angle by which the Earth will have rotated at the next LEO revolution, it is possible to combine a backward

limb observation followed by a dedicated sideward limb observation at the consecutive orbit. This mode is called tomographic because the same location is observed with a small delay of about 1.5 hours, from two almost orthogonal directions in equatorial regions, which allows for a 3-D inversion of the geophysical fields.

Even if the mission scenario of ALTIUS is driven by the baseline observation modes described above, the platform high manoeuvrability enables a pointing in many directions for dedicated and limited campaigns. Taking into account the total available power, thermal budgets, data transmission, exposition of star trackers to direct solar light, etc, the feasibility and programming of these campaigns will require case-by-case studies. Therefore they will only be implemented after successful commissioning. As a non-exhaustive list of dedicated observation modes, we can mention:

- Specific airglow emissions

- Lunar occultations

- Inter-validation with nadir looking instruments

- Volcanic events

- "Colour of clouds" measurements

- Effect of solar proton events

- "Tangent" occultations (celestial body doesn't set for a very obique occultation and is grazing the horizon)

- Polarization-sensitive measurements (by rotating the satellite)

- Photochemical effect of solar eclipses

\subsection{Multimode observations}

\subsubsection{Bright limb images}

In Fig. 12, bright limb radiance simulations have been obtained from the radiative transfer code MODTRAN 5, for a US standard atmosphere 1976 (mid-latitude summer model) with a background stratospheric aerosol load and no clouds. The tangent point is located at $45^{\circ} \mathrm{N}, 0^{\circ} \mathrm{E}$. ALTIUS looks at this location from a sun-synchronous orbit at 10:30 local time at descending node (LTDN), backward with respect to the platform velocity vector. The radiance was calculated for 19 tangent altitudes and exhibits a large dynamical range with respect to the tangent altitude. Subsequently, raw ALTIUS images were simulated for any wavelength in each channel. When possible, the pixel gain and the exposure time have been optimized to 
Atmos. Meas. Tech. Discuss., doi:10.5194/amt-2016-213, 2016

Manuscript under review for journal Atmos. Meas. Tech.

Published: 3 August 2016

(c) Author(s) 2016. CC-BY 3.0 License.

(c) (i)

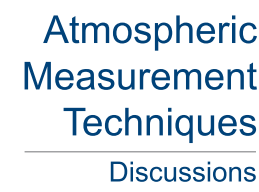

maximize the signal without saturation. In general, very little variation of signal can be seen along the horizontal direction. In Fig. 13, we show a typical ALTIUS bright limb image in the UV channel. The noise is representative of the total radiometric uncertainty and a vertical cross section allows to easily identify the radiometric knee.

\subsubsection{Solar occultation images}

5 The Sun is an extended light source of which the apparent solid angle is fully covered by the 2-D detectors. A model of solar absolute radiance field was developed in-house. At the moment, it is capable of simulating the high sun disk at any wavelength, including the solar limb darkening effect. A ray tracing model is also available to compute the path and the extinction through the atmosphere. Three images of the high Sun have been simulated in Fig. 14, one for each channel. The only radiometric difference between a bright limb acquisition and a Sun image is the insertion of a neutral density (ND) filter in the optical path by a mechanism.

\subsubsection{Star occultation images}

As observed by ALTIUS, stars are point-like sources slightly defocused by the point spread function (PSF) of each channel. Raw ALTIUS spectral images of stars are therefore essentially noise with a bright spot spread over a few pixels. A simple BeerLambert model has been developed to simulate stellar occultations. It computes the refracted optical path and the extinction by all absorbing (or scattering) species through the atmospheric layers. In the current model, these radial layers are considered homogeneous with a thickness of $50 \mathrm{~m}$. For the simulation presented in Fig. 15, we used the out-of-atmosphere spectral irradiance of Sirius as measured by GOMOS, computed the extinction and solved the ray tracing problem for a standard atmosphere (summer mid-latitude, extinction by $\mathrm{O}_{3}, \mathrm{NO}_{2}$, aerosols and refractive dilution).

\subsection{In-flight calibrations}

Due to volume limitations, the platform will not be carrying calibrated light sources or spectroscopic references to monitor drifts of instrumental characteristics. Only vicarious methods will provide the needed information. When unavailable during nominal observations, calibration campaigns will require acquisitions and manoeuvres that will interrupt the baseline data production. The heliosynchronicity of the orbit will introduce repetitive patterns over different time scales (orbit, seasons) allowing for predictability of the change in performance. Also, the rather simple instrument design limits the sources of possible performance drift and it is expected that the time allocated to calibration campaigns will remain well below the limits of the 10 $\%$ spare mission time reserved for non-baseline operations. The imaging capability of ALTIUS is a strong advantage especially for the pointing calibration. Furthermore, the agility of the PROBA platform allows for a set of different approaches, potentially bringing any source of light in the field of view. Hereafter, three main calibration topics are identified: radiometric calibration (and image acquisition in general), pointing registration and spectral registration. 
Atmos. Meas. Tech. Discuss., doi:10.5194/amt-2016-213, 2016

Manuscript under review for journal Atmos. Meas. Tech.

Published: 3 August 2016

(c) Author(s) 2016. CC-BY 3.0 License.

\author{
Atmospheric \\ Measurement \\ Techniques \\ Discussions
}

(c) (i)

\title{
2.5.1 Radiometric calibration
}

Atmospheric limb sounding by the occultation technique is radiometrically self-calibrating because the transmittance along the optical path is computed by dividing the observed spectrum by an exo-atmospheric reference spectrum. Bright limb retrievals also rely on normalized measurements with respect to a reference spectral radiance recorded at a selected tangent altitude (generally above the vertical region of interest) and an absolute radiometric calibration is not mandatory . For photo-response non-uniformity (PRNU), no flat field device will be available on-board, so two possible approaches are considered

- to build a synthetic flat field from a number of cloudy scenes imaged at nadir: the complex patterns found in independent images are completely smoothed out by the random combination of tens of them.

- to use the Moon or the Sun as extended light sources that can be scanned across the field of view by a satellite manoeuvre.

Residual straylight analysis can be performed by making use of a slight depointing of the line-of-sight and, for the AOTF channels, by exploiting the deflection of the filtered beam at the selected wavelength (i.e. straylight issued from the complementary spectrum will not follow the same optical way).

\subsubsection{Pointing calibration and tangent altitude registration}

From flight experience with prior missions (f.i. PROBA-2), the PROBA platform has demonstrated a relative performance pointing error (RPE) of $25 \mu \mathrm{rad}$ (at $2 \sigma$ significance) over 5 seconds, well below the $100 \mu \mathrm{rad}$ for the ALTIUS required RPE. During limb scattering observations, the platform will be required to point the instrument LOS toward the local geoid at the horizon. The PROBA attitude and orbit control system (AOCS) uses three star trackers to determine the spacecraft attitude. This information will be time-tagged on every acquired image. In limb geometry, the AOCS is therefore the primary source of information for the determination of the instrument line of sight (LOS) pointing.

The on-ground calibration will determine the relationship between the star trackers LOS, and the individual boresight reference frames (BRF) of the three channels. As this relationship may change after launch (0-g relaxation) and under different thermo-elastic conditions (orbital and seasonal effects), there is a need for an independent assessment of the instrument pointing. Obviously, during occultations the absolute pointing is calibrated by astronomical ephemerides and it can be used to validate the AOCS information. This validated quantity can be re-used for bright limb measurements, although the relatively different illumination conditions, and hence thermo-elastic environments, have to be taken into account and modelled. The baseline approach for the validation of the star tracker information during bright limb measurements consists in identifying bright stars (or planets) shining through the highest atmospheric layers. This ensures that the star signal holds strong, and that no refractive effect perturbs the tangent altitude determination. It turns out that the likelihood of finding useful star candidates for almost any latitude is high. Eventually, the pointing calibration can also be cross-calibrated with respect to geographical details (on day side) and enlighted cities (on night side) with or without depointing toward nadir. 
Atmos. Meas. Tech. Discuss., doi:10.5194/amt-2016-213, 2016

Manuscript under review for journal Atmos. Meas. Tech.

Published: 3 August 2016

(c) Author(s) 2016. CC-BY 3.0 License.

(c) (i)

\author{
Atmospheric \\ Measurement \\ Techniques \\ Discussions
}

\subsubsection{Spectral calibration}

An AOTF can be easily swept over small small spectral windows containing known star spectral features (Fraunhofer lines). The identification of these features enables direct wavelength registration. With its spatial extension, the Sun is an ideal target and it also offers the possibility to discover wavelength shifts produced by thermal gradients inside the AOTF. In a spectral calibration simulation (using a sweep of spectral images of the Sun), the wavelength of the minimum of the hydrogen $\alpha$ Balmer absorption line around $656 \mathrm{~nm}$ could be determined by polynomial fit with an uncertainty of $0.13 \mathrm{~nm}$ with only one pixel, or virtually no uncertainty by summing all the pixels (see Fig. 16). For the FPI, the approach is a bit more complex as the peak transmission of the filter is a less smooth function of the mirror gap length (and hence as a function of wavelength). The direct identification of spectral features requires therefore the proper consideration of the filter response. As on-ground calibration will have provided accurate estimation of the FPI constants, the physical model of the filter will be available. Preliminary experiments with the solar spectrum around $360 \mathrm{~nm}$ have demonstrated that the de-tuning error can be detected with an uncertainty smaller than $0.1 \mathrm{~nm}$.

\section{Data processing}

\subsection{Data level definition}

The following definitions will apply to the ALTIUS data levels.

- LR concerns raw telemetry data as received at the downlink station

- L0 data product: formatted data frames produced from LR, checked for integrity and ingested into the mission data base/archive.

- L1 data product: Detector readouts calibrated and converted to geolocated physical units, after processing of all calibration protocols. L1 data processing is highly automatized but is verified with a quality assurance control.

- L2 data product: geophysical data produced from L1 data, further processed to such a level that scientific analysis can be performed for individual geolocated observations with error budget. During and after the mission, the algorithms are usually improved and validated; L2 data are therefore released with a reference to the used version of the data processing model (DPM). DPM optimization and quality assurance of L2 data need high level scientific expertise in atmospheric chemistry and physics. L2 data are archived and released to the user community.

- L3 data product: These are publishable science products, where L2 data products are used as input. L3 data are produced by combining different observations in order to produce gridded assimilated data, climatologies and times series. Assimilated L3 data will be released to support cross-validation and coverage gap filling that can, potentially, support time delayed operational objectives. 
Atmos. Meas. Tech. Discuss., doi:10.5194/amt-2016-213, 2016

Manuscript under review for journal Atmos. Meas. Tech.

Published: 3 August 2016

(c) Author(s) 2016. CC-BY 3.0 License.

(c) (i)

$\begin{array}{r}\text { Atmospheric } \\ \text { Measurement } \\ \text { Techniques } \\ \hline \text { Discussions }\end{array}$

\subsection{Processing chain}

\subsubsection{From L0 to L1 data}

Although there are a number of common steps, fundamental differences exist between limb and occultation data which deserve specific treatment. Similarly, solar occultations and stellar or planetary occultations have their own complexity related to the

5 fact that the Sun is an extended source whereas stars are point sources.

The first input to the L1 processing chain is obviously the ALTIUS L0 data. It consists of three types of files :

- the science data (the observed scene spectral intensity provided in the form of a matrix of integers) stored in one file per snapshot, and tagged with the acquisition time and the channel identifier.

- the payload ancillary data gathered in one file per spectral image, and tagged with the acquisition time and the channel identifier.

- the platform ancillary data collected as a time series of parameter values allowing for interpolation at the time of any particular image acquisition.

These data must be complemented by on-ground characterizations, in-flight calibrations and the best estimate of the polarization ellipse of the incoming radiance.

The $\mathrm{L} 1$ data processing stage then proceeds through the following fork:

- for bright limb images, in-flight calibration data combined with S/C attitude knowledge are used to determine the spatial coordinates of the tangent point (TP) of each pixel line of sight (LOS) above the reference geoid. Digital radiances (and their uncertainties) are computed for each pixel by taking into account the polarization state, and are flagged for the presence of clouds.

- for stellar occultations, two main differences exist: the atmospheric slant transmittance is obtained by dividing the star spectral irradiance by the measured exo-atmospheric reference; a ray tracing computation is performed based on ECMWF air/temperature data in order to determine the physical tangent altitude of the optical path and the refractive dilution factor to be applied (Fussen, 2015).

- for solar occultations, successive acquired sun images partially overlap. Each pixel of the Sun image is associated with a specific tangent altitude computed by ray tracing and a radial distance to the center of the unrefracted Sun that determines the solar limb darkening distribution. Overlapping tangent altitudes are recombined into a common grid.

It is worth pointing out a small difference, related to LOS sampling, between grating based spectrometers and spectral imagers. The former record all useful wavelengths at once but at a fixed tangent altitude. The latter capture all tangent altitudes at once but at a fixed wavelength for each channel during the integration time (although the 3 ALTIUS channels operate independently). Both remote sensing techniques assume a locally homogeneous spherical atmosphere in order to apply simple 
Atmos. Meas. Tech. Discuss., doi:10.5194/amt-2016-213, 2016

Manuscript under review for journal Atmos. Meas. Tech.

Published: 3 August 2016

(c) Author(s) 2016. CC-BY 3.0 License.

(c) (i)

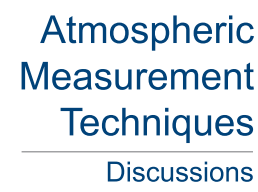

inversion techniques (not tomographic ones). The same remark holds for limb scattering as for occultations where the instantaneous tangent point may move by several degrees in latitude and/or longitude. This sampling is however consistent with the geometrical property of atmospheric remote sounding from a LEO satellite. Most of the geophysical information arises from the region around the tangent point, whose effective optical length is about $\sqrt{2 \pi R H} \approx 500 \mathrm{~km}$ where $R$ and $H$ respectively stand

5 for Earth radius and atmospheric scale height. The typical duration of an ALTIUS limb scattering observation is $10 \mathrm{~s}$ which corresponds to about a $70 \mathrm{~km}$ along-track displacement for a LEO orbit. Also, if the number of limb scattering observations per orbit could be increased up to 100 (instead of 50) depending on the final platform performance, the possibility of along-track tomographic retrievals from successive observations, compatible with the vertical sensor resolution, will be considered in the operational data processing.

\subsubsection{Radiative transfer}

The development of the ALTIUS radiative transfer models is a long term activity driven by a trade-off between speed and accuracy, for all considered observation modes. Hereafter, we simply outline the general frame in which the relevant algorithms will be constructed, tested, optimized and finally integrated in a so-called forward model.

The density distribution of the atmospheric trace constituents is not observable directly. The remote sensing of an atmosphere is only made possible by measuring the electromagnetic energy outgoing from the atmosphere. The observed energy is the result of absorption and scattering processes, caused by the atmospheric constituents, that modify the limb radiance and/or by thermal radiation generated in the atmosphere itself. To determine trace constituent densities thus requires solving the following inverse problem: given an observed radiation field, calculate the atmospheric composition that produced this observation.

It is the task of the retrieval algorithm to solve this inverse problem. This is typically done by minimising the difference between the observed radiation and the radiation calculated by a model of the atmosphere, in an iterative loop by adjusting the trace constituent densities in the atmospheric model. The model that calculates the radiation, produced by an atmosphere with a given composition, is called the forward model.

An acceptable forward model must be capable of accurately and efficiently simulating the following key properties and effects:

1. Oblate spheroid geometry of the atmosphere

2. Polarization of the light

3. Atmospheric refraction

4. Single (Rayleigh) scattering by the air molecules (in the IR)

5. Ground albedo contribution

6. Linearized single scattering model calculation

7. Orbital movements of the Earth (w.r.t. the Sun) and ALTIUS (w.r.t. Earth) 
Atmos. Meas. Tech. Discuss., doi:10.5194/amt-2016-213, 2016

Manuscript under review for journal Atmos. Meas. Tech.

Published: 3 August 2016

(c) Author(s) 2016. CC-BY 3.0 License.

(c) (i)

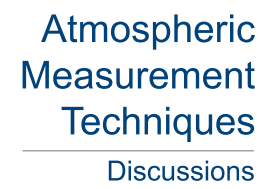

$\begin{array}{r}\text { Atmospheric } \\ \text { Measurement } \\ \text { Techniques } \\ \hline \text { Discussions }\end{array}$

8. Presence of molecules having spectra composed of many individual absorption lines (in the IR)

9. Multiple scattering by the air molecules (in the UV-Vis)

10. Linearized multiple scattering model calculation

The ALTIUS team is presently developing a radiative transfer model (RTM) that will address all above-mentioned features.

5 The performance of the RTM will be assessed with respect to several existing RT codes:VLIDORT-2.4 (Spurr, 2006), SIRO-2.2 (Oikarinen, 1999), SCIATRAN-3.1 (Rozanov, 2000) and SASKTRAN (Zawada, 2015).

In the future, we will consider two strategies to compute the polarization and multiple scattering effects in the radiance field:

1. The classical approach, which is to build a set of Stokes vector lookup tables, produced for an ensemble of atmospheric configurations and a grid of observational geometries, by running an accurate (possibly slow) tool, such as a Monte-Carlo program. In the retrieval algorithm loop, we can then interpolate over these tables to determine the Stokes vector for the atmospheric configuration at hand. We will typically need to tabulate over at least 6 dimensions: albedo, wavelength, tangent height, solar zenith angle, view direction zenith angle and relative azimuth angle between the solar and view direction (see table 4).

2. A more refined approach, which also starts by building a set of lookup tables as in the first strategy, and then is followed by a fitting stage, in which a small set of fit functions are derived that efficiently (w.r.t. speed and data requirements) can reproduce the data in the tables. These functions could e.g. represent a multiplicative correction factor function, with domain in the above 6-dimensional space and defined as the ratio of the total scattering divided by the single scattering contribution. Such a correction factor could be applied to the Stokes vector that is in-scattering at each point of the half-line of sight.

For the trace gas retrieval, the RTM will represent the forward model, i.e. a single scattering algorithm with multiple scattering corrections.

In the infrared domain, we will consider the correlated-k method (Mlawer, 1997; Lacis, 1991), a technique that is often used to reduce the number of wavelength points for which monochromatic RT calculations have to be done. The basic idea of the method is to sort the wavelengths according to the absorption coefficient at these wavelengths. On the re-ordered wavelengths grid the spectrum is smooth and monotonic, so very few quadrature points are needed for the spectral convolution. The advantages of this method are that it is very efficient and conceptually easy. Instead of having to do several thousands of monochromatic RT calculations, this can now be reduced to typically 10 to 40 . A disadvantage of this technique is that the exact sorting depends on pressure, temperature, and trace gas concentration. We intend to combine the fine resolution spectral data (computed in a line-by-line approach) and the correlated-k method to produce a broadband model, for a number of absorption line complexes of a number of chosen trace gases $\left(\mathrm{H}_{2} \mathrm{O}, \mathrm{CO}_{2}, \mathrm{CH}_{4}\right.$ and $\left.\mathrm{O}_{2}\right)$. The output of this broadband model will be in the form of cross section tables, structured in such a way that they can serve as input files for the RTM. 
Atmos. Meas. Tech. Discuss., doi:10.5194/amt-2016-213, 2016

Manuscript under review for journal Atmos. Meas. Tech.

Published: 3 August 2016

(c) Author(s) 2016. CC-BY 3.0 License.

\author{
Atmospheric \\ Measurement \\ Techniques \\ Discussions
}

(c) (i)

\title{
3.2.3 From $\mathrm{L} 1$ to $\mathrm{L} 2$ data
}

For bright limb retrievals, it is a common practice to avoid the need for absolute radiometric calibration by normalizing the signals found at the target tangent altitudes with respect to a reference taken at a higher altitude. This renormalization also allows to remove an important part of the ground albedo/cloudiness effects to the extent that all altitudes are similarly affected.

5 The efficiency of the normalization (f.i. with respect to a reference radiance at $40 \mathrm{~km}$ ) has been estimated by comparing the relative difference of normalized radiances with and without albedo effects taken into account in the RT model (see Figure 17). Above $15 \mathrm{~km}$, the error made by neglecting the albedo $(\mathrm{A}=0)$ when using normalized radiances is always smaller than $6 \%$, in the most perturbative case $(\mathrm{A}=1)$. Considering the error spectral dependence, a further normalization with data at a relatively close wavelength will virtually suppress it.

ALTIUS measurements will consist of spectral images capturing a scene of $100 \times 100 \mathrm{~km}^{2}$ at the tangent point without the need of any scanning mechanism. The detector pixel density enables an unmatched spatial sampling of the geophysical scene. For instance, the visible channel will provide independent measurements every $200 \mathrm{~m}$, typically one order of magnitude finer than all previous UV-VIS-NIR limb-scatter instruments or microwave emissions sounders. In addition, the absence of scanning also improves the knowledge on the LOS tangent height which is a crucial parameter for constituents exhibiting steep vertical concentration gradients. On the other side, unlike classical grating spectrometers, a limited number of spectral micro-windows has to be selected. This is a well-known trade-off in spectral remote sensing: a full high-resolution spectrum increases the statistics (more spectral values) but decreases the $\mathrm{S} / \mathrm{N}$ ratio per spectral pixel while medium-resolution microwindows allow focus on specific absorbers with higher S/N ratio. For ALTIUS, the number of used wavelengths is conditioned by the luminosity of the instrument and the brightness of the light source, both of which drive the detectors exposure time, and by the spectral information content of the target absorber optical thickness. However, the tunability of the AOTF and FPI will preserve the freedom of choice for the measurement wavelengths.

The approach here will consist of selecting the best set of wavelengths that maximizes the sensitivity to a particular constituent. First, the measured radiances will be processed to correct for the relative response non-uniformity across the FOV, then normalized by a higher altitude measurement at the same wavelength, and finally assembled in doublets or triplets (multiplets) involving two or more wavelengths. These multiplets will be compared to the corresponding output of a radiative transfer (RT) model and will trigger an iterative optimization of the trace gases concentration profiles.

As the full RT of ALTIUS is still under development, the scalar commercial code MODTRAN 5 (Berk, 2006) has been used to assess the achievable mission performance. The retrieval of vertical concentration profiles from multispectral images is a standard inversion problem, for which we followed the widely used Bayesian approach described in Rodgers (2000).

For occultations, the SNR depends on the selected light source. For solar occultation, the source always displays the same characteristics: a wealth of available light, a finite angular extension, and a spectral output that has a maximum at visible wavelengths. Stellar occultations use point-like light sources with properties that are characterized by star magnitude and temperature. Retrieval quality changes for each individual star: bright hot stars (strong UV output) will deliver accurate strato- 
Atmos. Meas. Tech. Discuss., doi:10.5194/amt-2016-213, 2016

Manuscript under review for journal Atmos. Meas. Tech.

Published: 3 August 2016

(c) Author(s) 2016. CC-BY 3.0 License.

(c) (i)

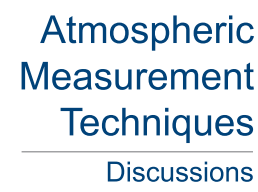

spheric and mesospheric ozone retrievals, while bright cold stars will favorize retrievals for species that are spectrally active in the infra-red $\left(\mathrm{CH}_{4}, \mathrm{H}_{2} \mathrm{O}\right)$.

The inversion algorithm proceeds through standard steps i.e. Rayleigh scattering removal, dilution and residual scintillation (stars only) removal, spectral inversion in global or differential modes, vertical inversion with regularization or a priori infor-

5 mation. The forward model is less complex in comparison with the limb case: it is based on the Beer-Lambert law for optical extinction.

\subsubsection{From L2 to L3 data}

Due to their intrinsic capacity to measure on both day and night sides, limb emission instruments can perform observations at twice the daily sample density of sensors observing solar limb scattering. Furthermore, they are still operational in polar night. On the other hand, the global coverage of ALTIUS is obtained by its multi-mode nature: the solar, stellar and planetary occultations provide sparse data at virtually all latitudes on the dark side of the orbit, while the bright limb measurements provide a regular and dense sampling on the day side. Therefore, on top of the L1/L2 data set (the data levels usually released to the user community), we are considering the added value of merging the data obtained from different observation modes through an assimilation scheme to produce L3 data. In addition to merging the different type of ALTIUS observations, this also offers gridded data at the global coverage to allow for fast validation or other applications. L3 data production will be performed with the Belgian Assimilation System for Chemical ObsErvations (BASCOE) which is focussed on the stratosphere (Errera, 2008). This system is based on a Chemistry Transport Model (CTM) that includes 58 chemical species interacting through around 200 chemical reactions. The chemical species are advected by meteorological dynamics imported from ECMWF (ERAInterim or the operational data). Typical spatio-temporal grid size is $2.5^{\circ}$ in latitude, $3.75^{\circ}$ in longitude with 37 levels from the surface up to $0.1 \mathrm{hPa}$ and a time step of 30 minutes. This system has been used in the pre-operational project on Monitoring the Atmosphere Composition and Climate (MACC) to deliver near real time analysis of MLS observations (Lefever, 2015).

This complementary processing of ALTIUS retrievals has two objectives:

1. to compensate the lower sampling density of ALTIUS by integrating all observations into a data field with a coverage similar to emission instruments

2. to offer gridded data with global coverage to allow for fast validation and application as data assimilation is the best way to correctly interpolate sparse data.

BASCOE is a data assimilation system dedicated to stratospheric chemical observations. The aim of data assimilation is to combine information embedded in real observations and in a numerical model in order to get the 'best' estimate of the atmospheric (or oceanographic) state. In the case of BASCOE, observations are assimilated with an assimilation window of 24 hours and the analysis, i.e. the optimized model field, are given at 0 UT. Then the model produces a short term forecast of 24 hours to provide the background state for the assimilation of the next day, and so on. 
Atmos. Meas. Tech. Discuss., doi:10.5194/amt-2016-213, 2016

Manuscript under review for journal Atmos. Meas. Tech.

Published: 3 August 2016

(c) Author(s) 2016. CC-BY 3.0 License.

(c) (i)

$\begin{array}{r}\text { Atmospheric } \\ \text { Measurement } \\ \text { Techniques } \\ \hline \text { Discussions }\end{array}$

\subsection{ALTIUS performance}

\subsubsection{Expected general performance}

The development of optimal retrieval algorithms for different species and observation geometries is a long term work that will extend up to the mission commissioning phase and even further if the in-flight instrument characterization deviates from the 5 requirements. The Data Processing Model (DPM) is therefore an ongoing activity. The capability of retrieving a set of constituent profiles from ALTIUS synthetic limb scattering and occultation measurements has been assessed. Three major sources of instrumental error (i.e. measurement noise, pointing error and wavelength misregistration) were included. Other measurement errors (f.i. in-field straylight level) are not yet well characterized and were kept fixed to their requirement levels. The same approach has been followed for each retrieved species. First, a near optimal set of relevant wavelengths was identified based on the heritage of previous missions when existing, or from trials otherwise. Second, an error-free retrieval was performed. Third, retrieval precision and accuracy were evaluated from synthetic measurements that were perturbed according to radiometric, pointing and spectral errors. Finally, a global error budget was computed and compared to the ALTIUS level-2 requirements.

In Table 5 we summarize the present status of the DPM results with respect to target and threshold objectives.

\subsubsection{Expected ozone performance}

Ozone vertical profiles being the first target of ALTIUS, extended simulations have been performed to assess the performance level. For limb scattering observations, we report in Fig. 18 an example of the retrieved concentration profile. The corresponding individual error sources are presented in Table 6.

As expected, ozone retrievals are of good quality for solar occultations. Errors are mainly due to imperfect pointing. The profiles are retrieved at sampling resolution from 20 to $80 \mathrm{~km}$. The results are presented in Fig. 19. Unsurprisingly, stellar occultations show more noise due to measurement error, since SNR is lower. Furthermore, some residual scintillation may remain, depending on the integration time and on the obliquity of the occultation plane. However, the effect is moderate (see Fig. 20 where the ozone absorption in the Chappuis band is easily identified) and will be numerically removed in further studies.

\subsubsection{Merging of multiple observation modes at L3 level}

25 By making use of a dedicated data assimilation system like BASCOE, it can be shown that the ensemble of ALTIUS measurements feeds an ozone analysis with a quality equivalent to the analysis obtained the assimilation of MLS data. In order to compute this ALTIUS synthetic data assimilation, observations (solar, stellar, moon and planet occultations, and bright limb) have been generated from a BASCOE analysis of MLS observations. This has been done for the period between June and September 2008. The ALTIUS synthetic data have been assimilated by BASCOE where the initial conditions on June 1st are twice larger than the analysis of MLS. Also, the model used in that assimilation experiment has its chemical scheme turned off. This ensures that the model used to generate these observations is different from the model used to assimilate them. As 
Atmos. Meas. Tech. Discuss., doi:10.5194/amt-2016-213, 2016

Manuscript under review for journal Atmos. Meas. Tech.

Published: 3 August 2016

(c) Author(s) 2016. CC-BY 3.0 License.

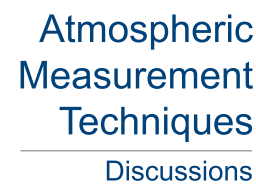

(c) (i)

an example, Fig. 21 shows the ozone partial column between 10 and $100 \mathrm{hPa}$ from the analysis of MLS and the analysis of ALTIUS. The result of a free model run (without assimilation) is also shown. This example proves that the ALTIUS spatial coverage allows to constrain the BASCOE ozone field during the polar night, as MLS observations do. A series of additional assimilation experiments have been performed in order to evaluate the impact of the different observation modes of ALTIUS

5 (Fig. 21). It is found that during the polar night, stellar and solar occultations are necessary to constrain ozone in the polar region. When the sunlight comes back at the end of the winter, bright limb observations are those that provide the stronger constrain on the analysis. This illustrates how sparse occultations can improve the prediction of global ozone fields when not enough limb data are available (from June to August) in the polar night.

\section{Conclusions}

From a LEO heliosynchronous orbit, ALTIUS will image the Earth's limb in the near UV, visible and near IR spectral regions to obtain concentration profiles of primarily $\mathrm{O}_{3}, \mathrm{NO}_{2}, \mathrm{H}_{2} \mathrm{O}$ and $\mathrm{CH}_{4}$ as well as aerosol extinction profiles. Due to the agility of the selected spacecraft platform, the instrument is capable of performing measurements in limb scattering, solar occultation and stellar occultation modes. It offers the possibility of rapid on-request changes of targets to perform dedicated scientific observations in addition to the baseline measurements. The principle of spectral imaging allows for improved tangent altitude registration when observing diffuse atmospheric radiances. It also allows for occultation measurements in inertial pointing mode without a complex tracking system.

By rotating the spacecraft in successive orbits, ALTIUS offers the possibility of performing tomography by observing an air volume from different viewing directions. This innovative tomographic mode is particularly valuable for observations of steep horizontal gradients, e.g. at the edge of the polar vortex. Furthermore, it allows a cross-mode (limb vs. occultation) self-validation of data sets.

As a UV-VIS-NIR instrument, ALTIUS will also be sensitive to a number of other parameters that are usually difficult to take into account in retrieval models (albedo, aerosol content, multiple scattering, etc.). These sources of error are not specific to ALTIUS, and in most cases, their impact on the retrieval performance will not be different for ALTIUS than for other UV-VIS-NIR sensors.

Two main scientific questions will be addressed by ALTIUS. The first one relates to the confirmation of the ozone recovery in link with the effectiveness of the Montreal Protocol. The second one expresses a fundamental need to quantify the stratospheric contribution of ozone, aerosols, water vapor and methane changes to climate forcing. Another important aspect of the ALTIUS mission is its complementarity to the ESA operational Sentinel-4, 5, and 5P missions, which are dedicated to monitoring the composition of the atmosphere for the Copernicus Atmosphere Services. ALTIUS measurements have the potential to help validate and improve the tropospheric ozone, tropospheric $\mathrm{NO}_{2}$ and tropospheric methane columns from these nadir sounders.

At this time, the ALTIUS project has completed its phase B1 development, and is on its way toward a Preliminary Design Review of the whole system. It has undergone several successful reviews of the mission concepts and performance requirements. As already mentioned, it recently became a new element of the Earth Watch programme of the ESA Earth Observation 
Atmos. Meas. Tech. Discuss., doi:10.5194/amt-2016-213, 2016

Manuscript under review for journal Atmos. Meas. Tech.

Published: 3 August 2016

(c) Author(s) 2016. CC-BY 3.0 License.

(c) (i)

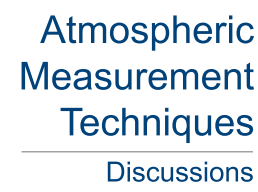

division. Future work on the ALTIUS mission will require an integrated approach of payload, platform and ground segment. This will be implemented as an integrated project covering flight segment, ground segment and end-to-end performance with urgent initiation of all required pre-developments.

Acknowledgements. The ALTIUS project has been fully supported by the Belgian Scientific Policy Office (BELSPO) through several con-

5 tracts funded within the ESA-PRODEX programme. We want to express our gratitude to the BELSPO space team and particularly to Steven Bogaerts, Pierre Coquay, Jacques Nijskens and Jean-Christophe Schyns. Many people have contributed to the mission technical studies. At the Belgian Institute for Space Aeronomy, we are very grateful to Christine Bingen, Simon Chabrillat, Philippe Demoulin and Vitaly Voloshinov for their scientific support and to the Engineering team with special thanks to Sophie Berkenbosch, Nicolas Loodts, Jeroen Maes, Eddy Neefs, Dennis Nevejans, Jurgen Vanhamel, Bert Van Opstal and Emiel Van Ransbeeck. On the industrial side, we want to thank our main partners. The OIP company was in charge of payload studies with essential contributions from Ludovic Aballea, Kasper De Geeter, Lieve De Vos and Wouter Moelans. QinetiQ Space has adapted the PROBA platform with a deep involvement of Dirk Bernaerts, Dennis Gerrits, Jauris Naudet, Davy Vrancken and their collaborators. Finally, we also received much support from people at ESA-EO and ESA-DTEC. The PRODEX office, under leadership of Michel Lazerges, played a crucial role to sustain our activities whereas a very appreciated support was given by Marline Claessens and Nicholas Lan. 
Atmos. Meas. Tech. Discuss., doi:10.5194/amt-2016-213, 2016

Manuscript under review for journal Atmos. Meas. Tech.

Published: 3 August 2016

(c) Author(s) 2016. CC-BY 3.0 License.
Atmospheric

Measurement

Techniques

Discussions

\section{References}

Berk, A., G.P. Anderson, P.K. Acharya, L.S. Bernstein, L. Muratov, J. Lee, M. Fox, S.M. Adler-Golden, J.H. Chetwynd, M.L. Hoke, R.B Lockwood, J.A. Gardner, T.W. Cooley, C.C. Borel, P.E. Lewis and E.P. Shettle, "MODTRAN5: 2006 Update," Proc. SPIE, Vol. 6233, $62331 \mathrm{~F}, 2006$.

5 Chang I. C., "Noncollinear acousto-optic filter with large angular aperture," Appl. Phys. Lett. 25, 370-372,1974.

Dekemper E., Loodts N., Van Opstal B., Maes J., Vanhellemont F., Mateshvili N., Franssens G., Pieroux D., Bingen C., Robert C., De Vos L., Aballea L. and Fussen D., "Tunable acousto-optical spectral imager for atmospheric composition measurements in the visible spectral domain”, Appl. Opt. 51, 2012.

Deland, M. T., Shettle, E. P., Thomas, G. E., and Olivero, J. J., Latitude-dependent long-term variations in polar mesospheric clouds from SBUV version 3 PMC data, J. Geophys. Res., 112, D10315, doi:10.1029/ 2006JD007857, 2007.

Dupuy, E., Walker, K. A., Kar, J., Boone, C. D., McElroy, C. T., Bernath, P. F., Drummond, J. R., Skelton, R., McLeod, S. D., Hughes, R. C., Nowlan, C. R., Dufour, D. G., Zou, J., Nichitiu, F., Strong, K., Baron, P., Bevilacqua, R. M., Blumenstock, T., Bodeker, G. E., Borsdorff, T., Bourassa, A. E., Bovensmann, H., Boyd, I. S., Bracher, A., Brogniez, C., Burrows, J. P., Catoire, V., Ceccherini, S., Chabrillat, S., Christensen, T., Coffey, M. T., Cortesi, U., Davies, J., De Clercq, C., Degenstein, D. A., De Mazière, M., Demoulin, P., Dodion, J., Firanski, B., Fischer, H., Forbes, G., Froidevaux, L., Fussen, D., Gerard, P., Godin-Beekmann, S., Goutail, F., Granville, J., Griffith, D., Haley, C. S., Hannigan, J. W., Höpfner, M., Jin, J. J., Jones, A., Jones, N. B., Jucks, K., Kagawa, A., Kasai, Y., Kerzenmacher, T. E., Kleinböhl, A., Klekociuk, A. R., Kramer, I., Küllmann, H., Kuttippurath, J., Kyrölä, E., Lambert, J.-C., Livesey, N. J., Llewellyn, E. J., Lloyd, N. D., Mahieu, E., Manney, G. L., Marshall, B. T., McConnell, J. C., McCormick, M. P., McDermid, I. S., McHugh, M., McLinden, C. A., Mellqvist, J., Mizutani, K., Murayama, Y., Murtagh, D. P., Oelhaf, H., Parrish, A., Petelina, S. V., Piccolo, C., Pommereau, J.-P., Randall, C. E., Robert, C., Roth, C., Schneider, M., Senten, C., Steck, T., Strandberg, A., Strawbridge, K. B., Sussmann, R., Swart, D. P. J., Tarasick, D. W., Taylor, J. R., Tétard, C., Thomason, L. W., Thompson, A. M., Tully, M. B., Urban, J., Vanhellemont, F., Vigouroux, C., von Clarmann, T., von der Gathen, P., von Savigny, C., Waters, J. W., Witte, J. C., Wolff, M., and Zawodny, J. M.: Validation of ozone measurements from the Atmospheric Chemistry Experiment (ACE), Atmos. Chem. Phys., 9, 287-343, doi:10.5194/acp-9-287-2009, 2009.

Errera, Q., Daerden, F., Chabrillat, S., Lambert, J. C., Lahoz, W. A., Viscardy, S., Bonjean, S., and Fonteyn, D., 4D-Var assimilation of MIPAS chemical observations: ozone and nitrogen dioxide analyses, Atmos. Chem. Phys., 8(20):6169-6187, 2008.

Froidevaux, L. and Jiang, Y. B. and Lambert, A. and Livesey, N. J. and Read, W. G. and Waters, J. W. and Browell, E. V. and Hair, J. W. and Avery, M. A. and McGee, T. J. and Twigg, L. W. and Sumnicht, G. K. and Jucks, K. W. and Margitan, J. J. and Sen, B. and Stachnik, R. A. and Toon, G. C. and Bernath, P. F. and Boone, C. D. and Walker, K. A. and Filipiak, M. J. and Harwood, R. S. and Fuller, R. A. and Manney, G. L. and Schwartz, M. J. and Daffer, W. H. and Drouin, B. J. and Cofield, R. E. and Cuddy, D. T. and Jarnot, R. F. and Knosp, B. W. and Perun, V. S. and Snyder, W. V. and Stek, P. C. and Thurstans, R. P. and Wagner, P. A.: Validation of Aura Microwave Limb Sounder stratospheric ozone measurements, J. Geophys. Res., 113, D15S20, doi:10.1029/2007JD008771, 2008.

Fussen, D., Tétard, C., Dekemper, E., Pieroux, D., Mateshvili, N., Vanhellemont, F., Franssens, G., and Demoulin, P.: Retrieval of vertical profiles of atmospheric refraction angles by inversion of optical dilution measurements, Atmos. Meas. Tech., 8, 3135-3145, doi:10.5194/amt8-3135-2015, 2015.

Hegglin, M.I., S. Tegtmeier, J. Anderson, L. Froidevaux, R. Fuller, B. Funke, A. Jones, G. Lingenfelser, J. Lumpe, D. Pendlebury, E. Remsberg, A. Rozanov, M. Toohey, J. Urban, T. von Clarmann, K.A. Walker, R. Wang and K. Weigel, 2013: SPARC Data Initiative: Comparison of water vapor climatologies from international satellite limb sounders. J. Geopyhs. Res., doi: 10.1002/jgrd.50752, 2013. 
Atmos. Meas. Tech. Discuss., doi:10.5194/amt-2016-213, 2016

Manuscript under review for journal Atmos. Meas. Tech.

Published: 3 August 2016

(c) Author(s) 2016. CC-BY 3.0 License.

(c) (i)

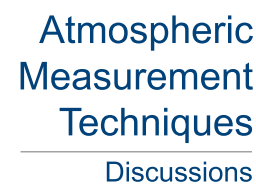

Lacis, A. A., Oinas, V. A description of the correlated k distribution method for modeling nongray gaseous absorption, thermal emission, and multiple scattering in vertically inhomogeneous atmospheres. J. Geophys. Res. 96 (D5), 9027-9063, 1991.

E J Llewellyn, N D Lloyd, D A Degenstein, R L Gattinger, S V Petelina, A E Bourassa, J T Wiensz, E V Ivanov, I C McDade, B H Solheim, J C McConnell, C S Haley, C von Savigny, C E Sioris, C A McLinden, E Griffioen, J Kaminski, W FJ Evans, E Puckrin, K Strong, V Wehrle, R H Hum, D JW Kendall, J Matsushita, D P Murtagh, S Brohede, J Stegman, G Witt, G Barnes, W F Payne, L Piché, K Smith, G Warshaw, D -L Deslauniers, P Marchand, E H Richardson, R A King, I Wevers, W McCreath, E Kyrölä, L Oikarinen, G W Leppelmeier, H Auvinen, G Mégie, A Hauchecorne, F Lefèvre, J de La Nöe, P Ricaud, U Frisk, F Sjoberg, F von Schéele, L Nordh: The OSIRIS instrument on the Odin spacecraft, Canadian Journal of Physics, 82(6): 411-422, 10.1139/p04-005, 2004.

Lefever, K., van der A, R., Baier, F., Christophe, Y., Errera, Q., Eskes, H., Flemming, J., Inness, A., Jones, L., Lambert, J.-C., Langerock, B., Schultz, M. G., Stein, O., Wagner, A., and Chabrillat, S. Copernicus stratospheric ozone service, 2009-2012: validation, system intercomparison and roles of input data sets. Atmos. Chem. Phys., 15, 2269-2293, doi:10.5194/acp-15-2269-2015, 2015.

Mlawer EJ, Taubman SJ, Brown PD, Iacono MJ, Clough SA. Radiative transfer for inhomogeneous atmospheres: RRTM, a validated correlated-k model for the longwave. J. Geophys. Res.;102: 16663-82, 1997.

Moy, L., Bhartia, P. K., Jaross, G., Loughman, R., Kramarova, N., Chen, Z., Taha, G., Chen, G., and Xu, P.: Altitude Registration of LimbScattered Radiation, Atmos. Meas. Tech. Discuss., doi:10.5194/amt-2016-103, in review, 2016.

L. Oikarinen, E. Sihvola and E. Kyrola, Multiple scattering radiance in limb-viewing geometry, J Geophys Res, 104, 31261-31274, 1999.

OSCAR, Observing Systems Capability Analysis and Review Tool, WMO, http://www.wmo.int/oscar/, 2016.

T. Ott, A. Benoit, P.Van den Braembussche and W. Fichter, ESA POINTING ERROR ENGINEERING HANDBOOK, 8th International ESA conference GNCC 2011, 2011

Rodgers C. D., Inverse methods for atmospheric sounding: Theory and practice Atmospheric, Oceanic and Planetary Physics, World Scientific, 2000.

Rozanov, V. Rozanov and J.P. Burrows, Combined differential-integral approach for the radiation field computation in a spherical shell atmosphere: Non-limb geometry, J. Geophys. Res., 105, 22937-22943, 2000.

Spurr, R.J.D., VLIDORT: A linearized pseudo-spherical vector discrete ordinate radiative transfer code for forward model and retrieval studies in multilayer multiple scattering media. J. Quant. Spectrosc. Radiat. Transfer, 102: p. 316-342, 2006.

Stocker, T.F., D. Qin, G.-K. Plattner, M. Tignor, S.K. Allen, J. Boschung, A. Nauels, Y. Xia, V. Bex and P.M. Midgley (eds.)], Climate Change 2013: The Physical Science Basis. Contribution of Working Group I to the Fifth Assessment Report of the Intergovernmental Panel on Climate Change, Cambridge University Press, Cambridge, United Kingdom and New York, NY, USA, 1535 pp, 2013.

J. Xu and R. Stroud, Acousto-Optic Devices: Principles, Design,and Applications, Wiley, 1992.

Zawada, D. J., Dueck, S. R., Rieger, L. A., Bourassa, A. E., Lloyd, N. D., and Degenstein, D. A.: High-resolution and Monte Carlo additions to the SASKTRAN radiative transfer model, Atmos. Meas. Tech., 8, 2609-2623, doi:10.5194/amt-8-2609-2015, 2015. 
Atmos. Meas. Tech. Discuss., doi:10.5194/amt-2016-213, 2016

Manuscript under review for journal Atmos. Meas. Tech.

Published: 3 August 2016

(c) Author(s) 2016. CC-BY 3.0 License.

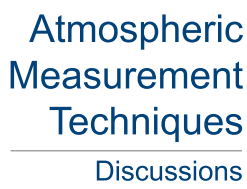

(c) (1)

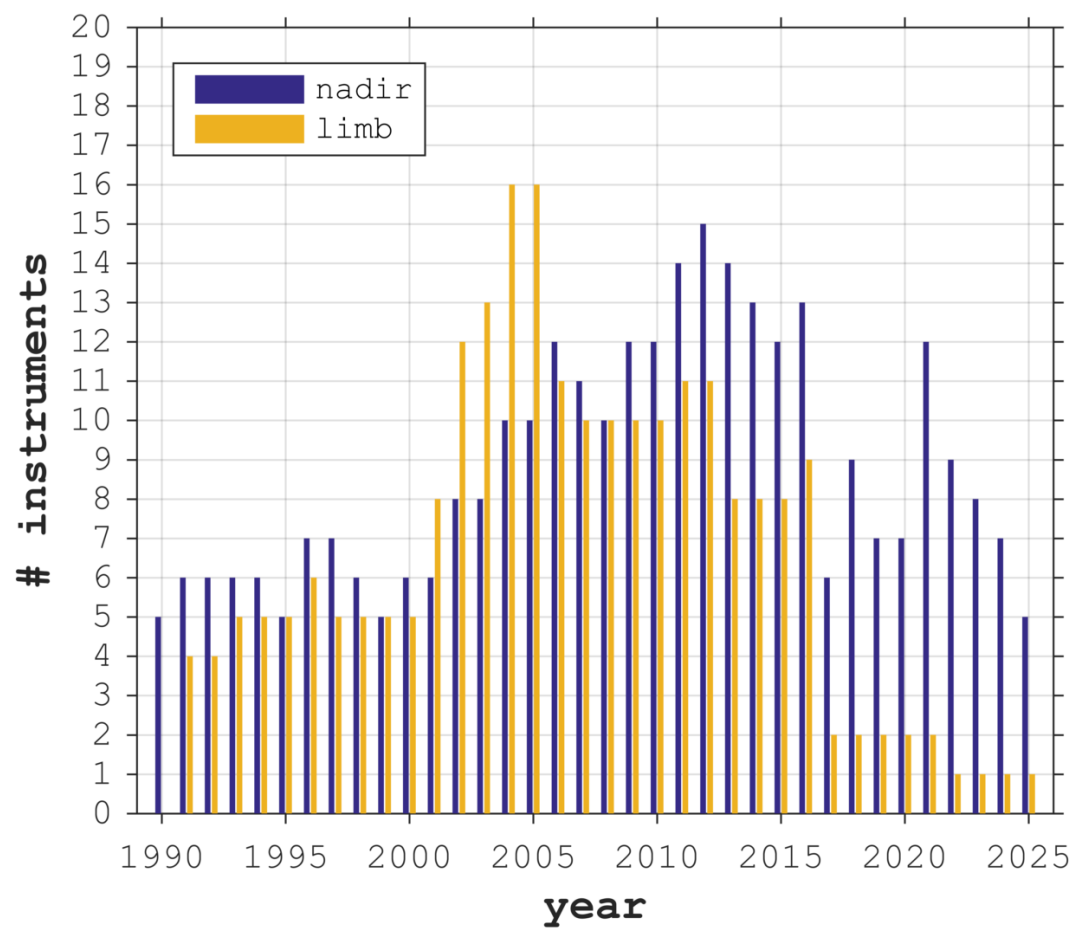

Figure 1. Evolution of the population of space-borne instruments with ozone measurement capabilities (Europe, North Amercia, Japan). In blue, the instruments providing total columns. In orange, those with good vertical resolution. The data have been retrieved from WMO's OSCAR database (OSCAR, 2016). 
Atmos. Meas. Tech. Discuss., doi:10.5194/amt-2016-213, 2016

Manuscript under review for journal Atmos. Meas. Tech.

Published: 3 August 2016

(c) Author(s) 2016. CC-BY 3.0 License.

\section{Atmospheric Measurement Techniques \\ Discussions}

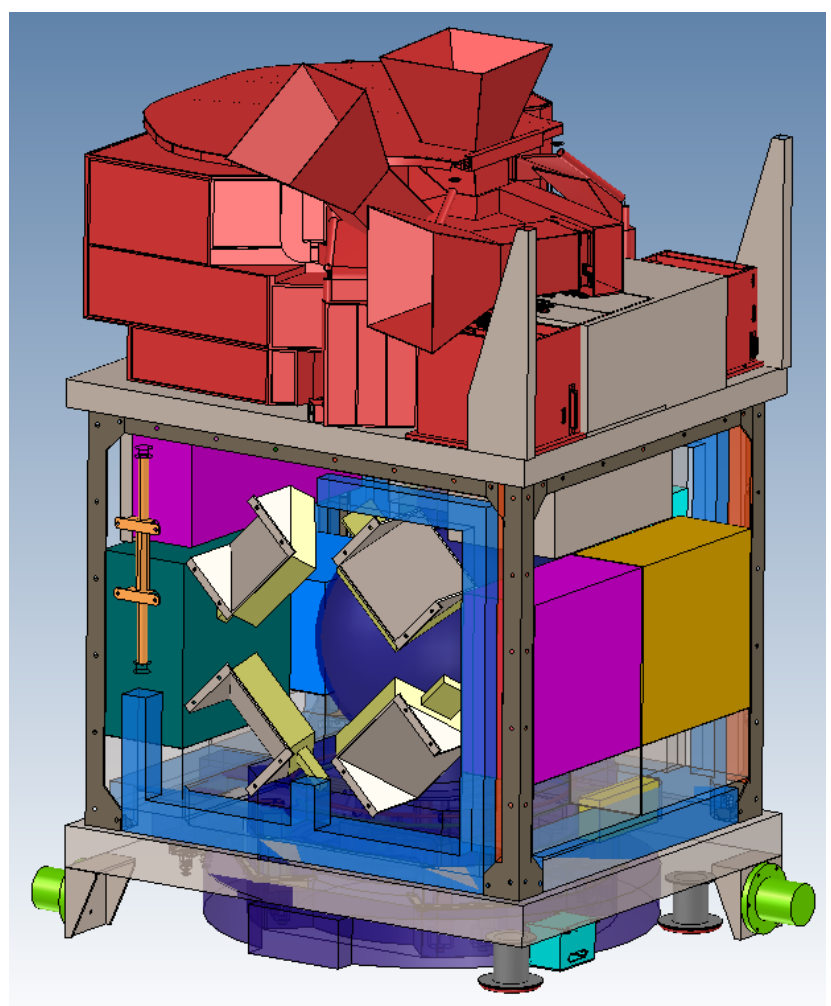

Figure 2. PROBA-ALTIUS internal view: the payload is red and equipped with three star trackers.

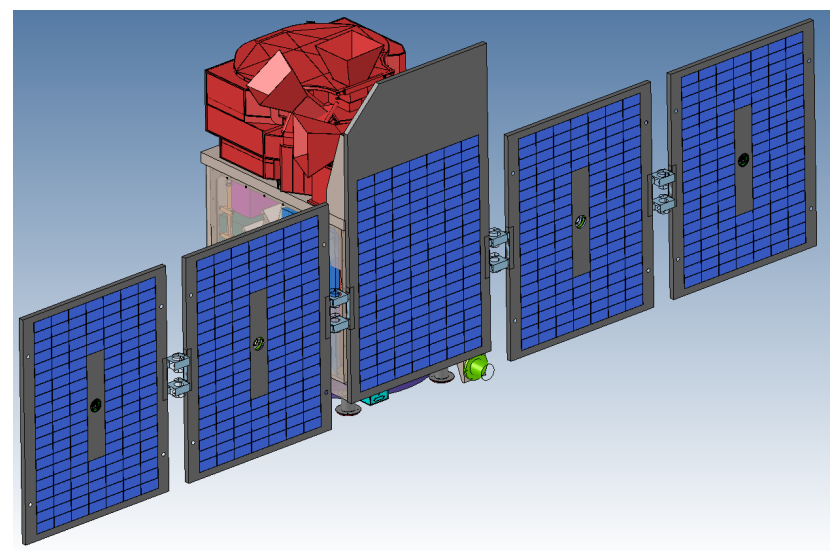

Figure 3. PROBA-ALTIUS external view with solar panels deployed. 
Atmos. Meas. Tech. Discuss., doi:10.5194/amt-2016-213, 2016

Manuscript under review for journal Atmos. Meas. Tech.

Published: 3 August 2016

(c) Author(s) 2016. CC-BY 3.0 License.

(c) (1)

\section{Atmospheric Measurement \\ Techniques \\ Discussions}

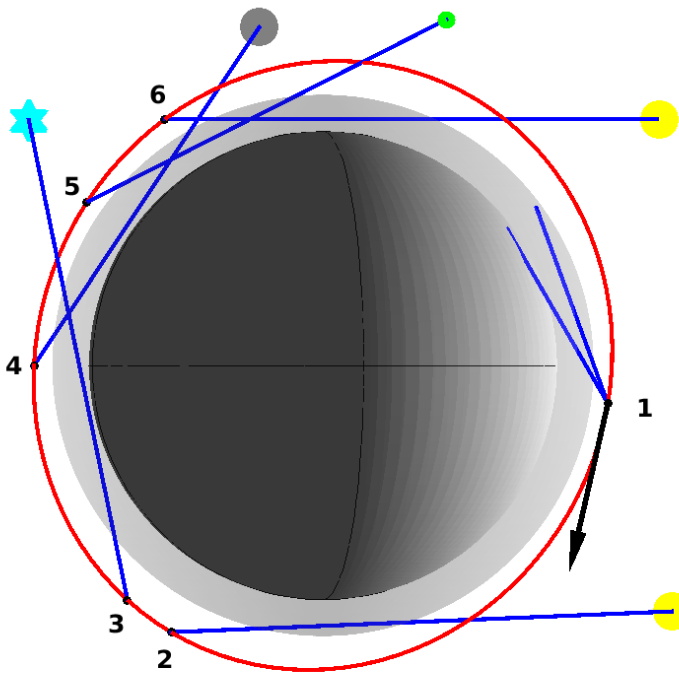

Figure 4. ALTIUS observation geometry and baseline operations: (1) backward limb (2) sunset occultation (3) star occultation (4) Moon occultation (5) planet occultation (6) sunrise occultation 
Atmos. Meas. Tech. Discuss., doi:10.5194/amt-2016-213, 2016

Manuscript under review for journal Atmos. Meas. Tech.

Published: 3 August 2016

(c) Author(s) 2016. CC-BY 3.0 License.

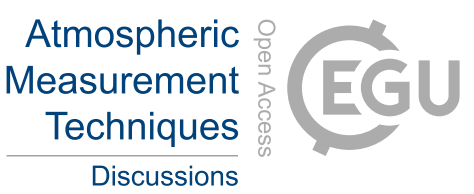

(c) (i)

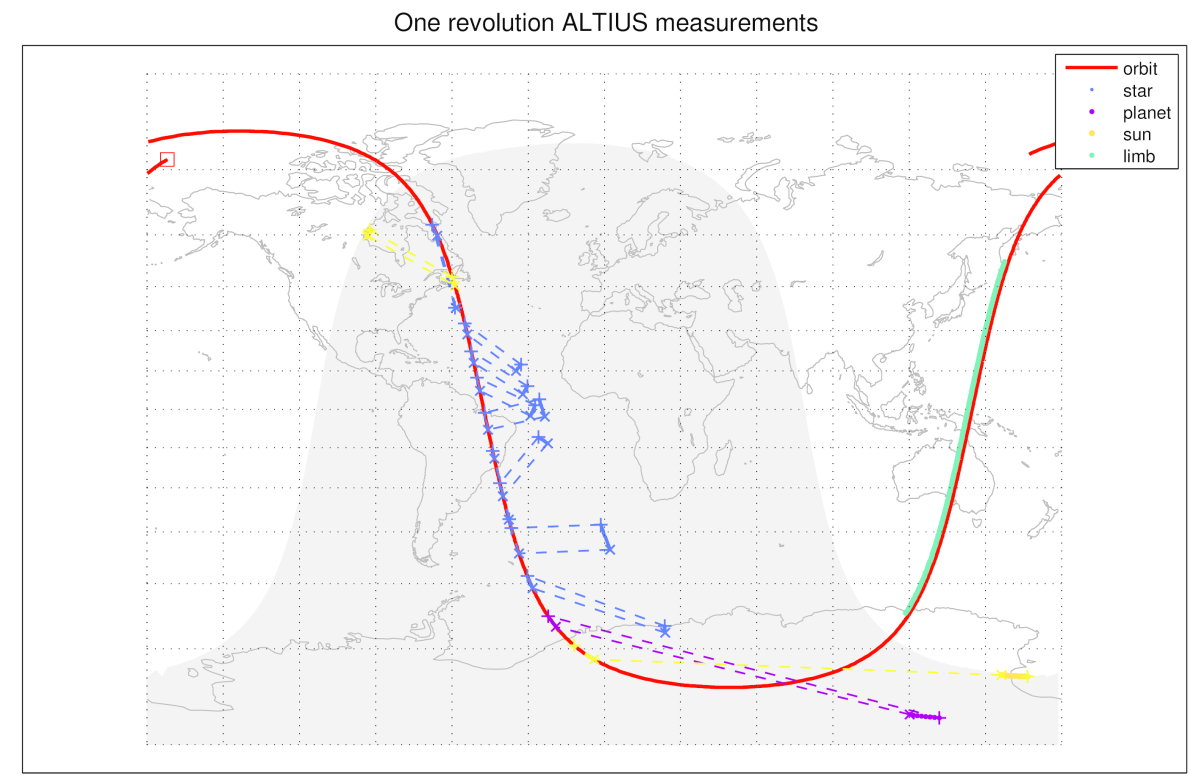

Figure 5. Observation in the baseline scenario for one revolution. ALTIUS successively performs limb (green) observations, solar occultations (yellow), planet occultation (magenta) and stellar occultations (blue) measurements. For the occultations, the geolocations of line-of-site tangent points are shown. The beginning and the end of the occultation measurements are associated with the corresponding orbit sectors. Only stars/planets with a magnitude brighter than 3 are considered. The terminator position was calculated at each longitude when the orbit crosses the longitude. 
Atmos. Meas. Tech. Discuss., doi:10.5194/amt-2016-213, 2016

Manuscript under review for journal Atmos. Meas. Tech.

Published: 3 August 2016

(c) Author(s) 2016. CC-BY 3.0 License.
Atmospheric

Measurement

Techniques

Discussions

(c) (i) $_{\mathrm{BY}}$

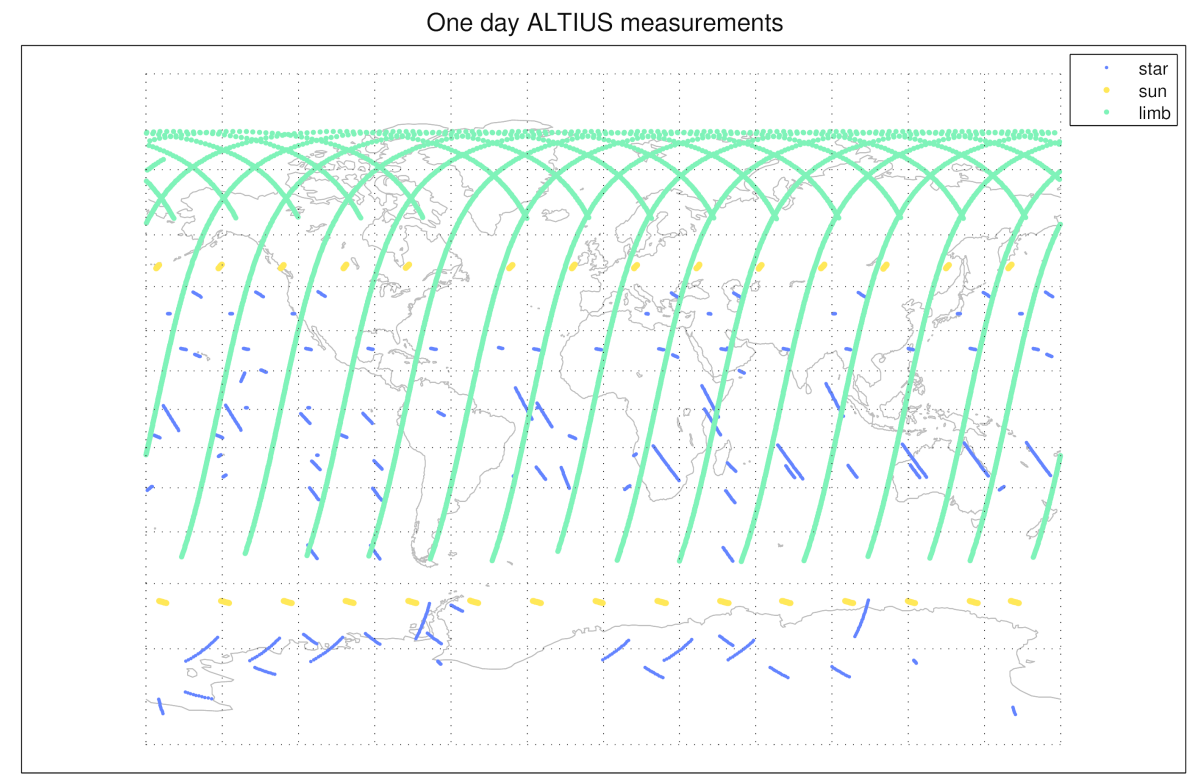

Figure 6. Daily coverage for the orbit (3-day revisit time). See text for the orbital parameters. Green: limb measurements, blue:stellar occultations, yellow: solar occultations.

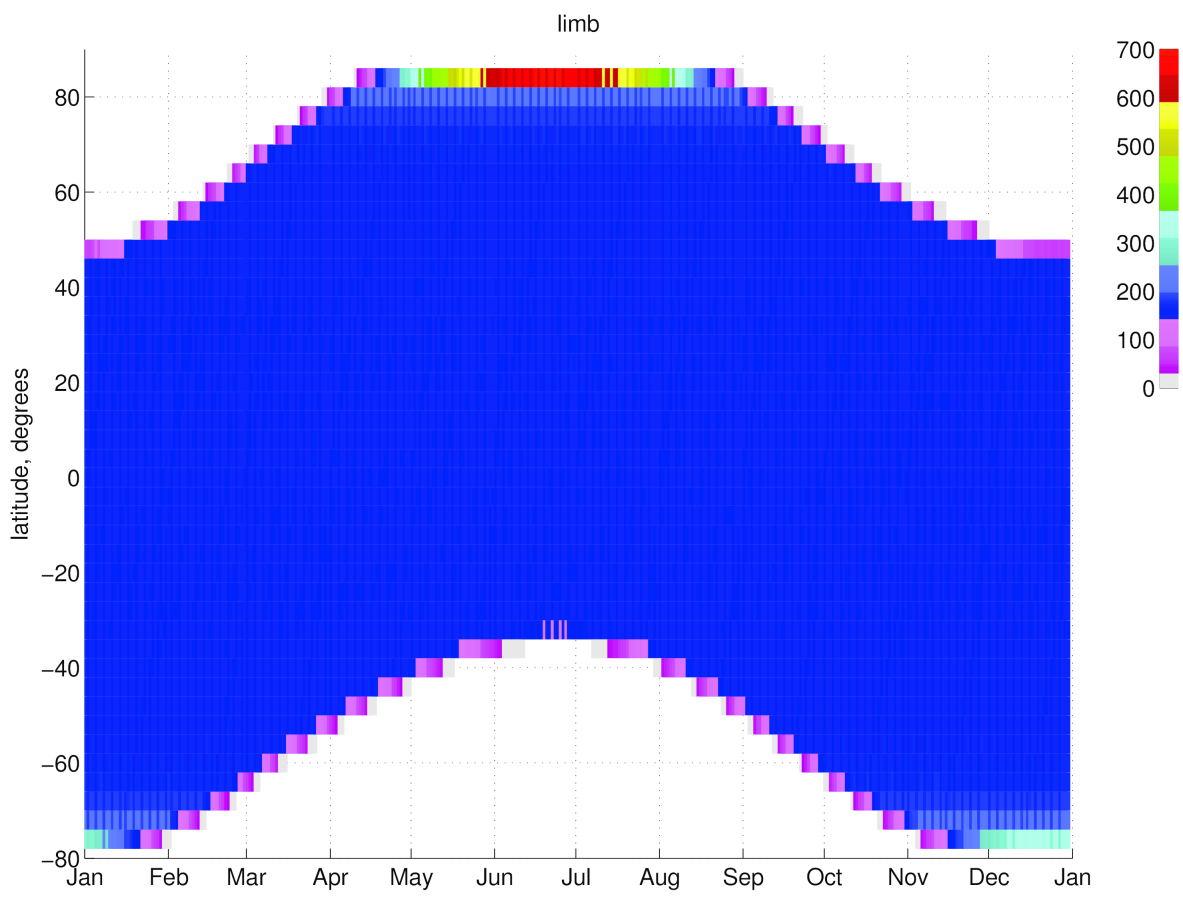

Figure 7. Annual coverage for bright limb observations, limited by the extension of the polar night. The maximal solar zenith angle at the tangent point is about $70^{\circ}$. The color scale refers to the number of observations. 
Atmos. Meas. Tech. Discuss., doi:10.5194/amt-2016-213, 2016

Manuscript under review for journal Atmos. Meas. Tech.

Published: 3 August 2016

(c) Author(s) 2016. CC-BY 3.0 License.

(c) (i)
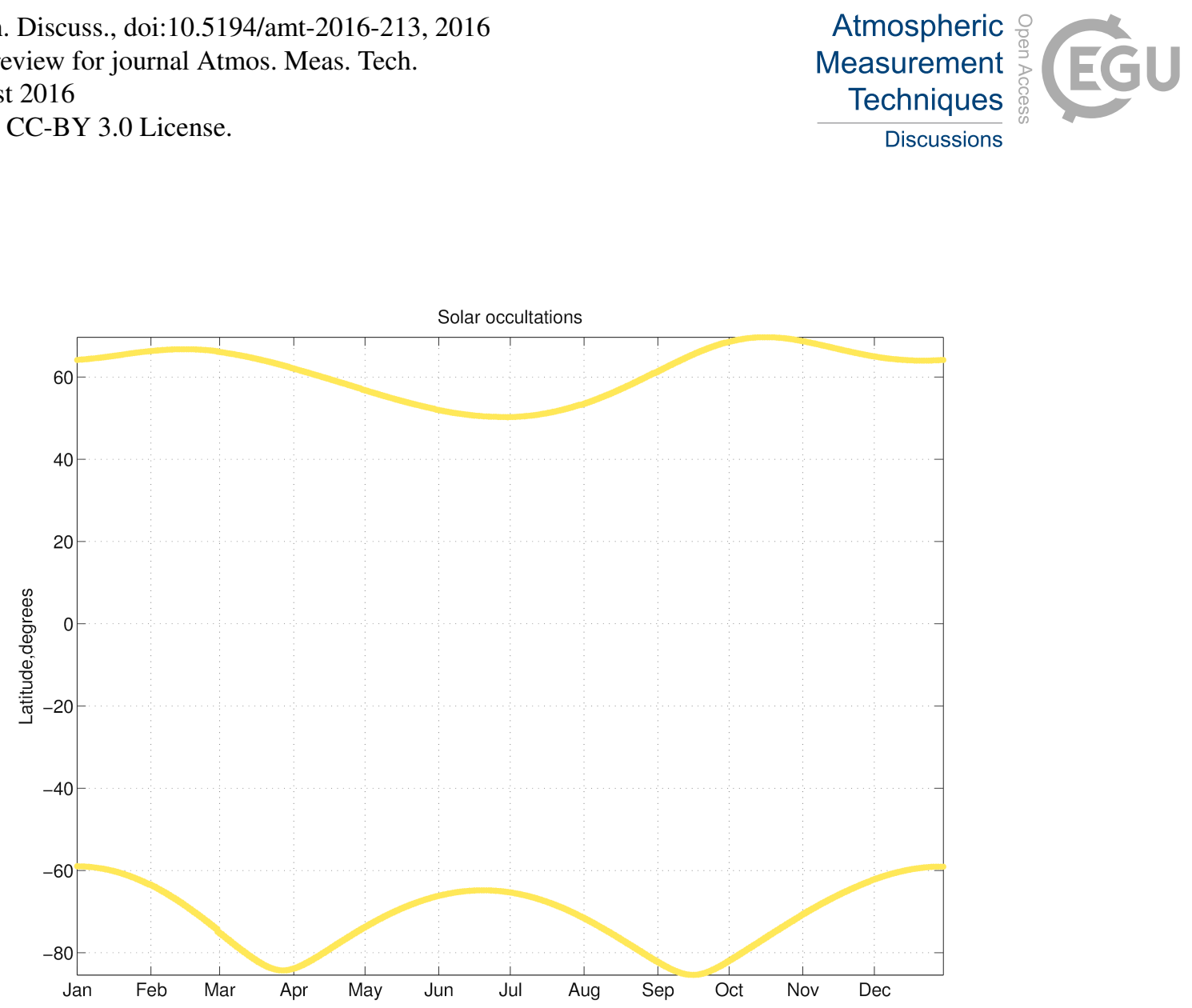

Figure 8. Annual coverage of solar occultations (sunrises and sunsets).

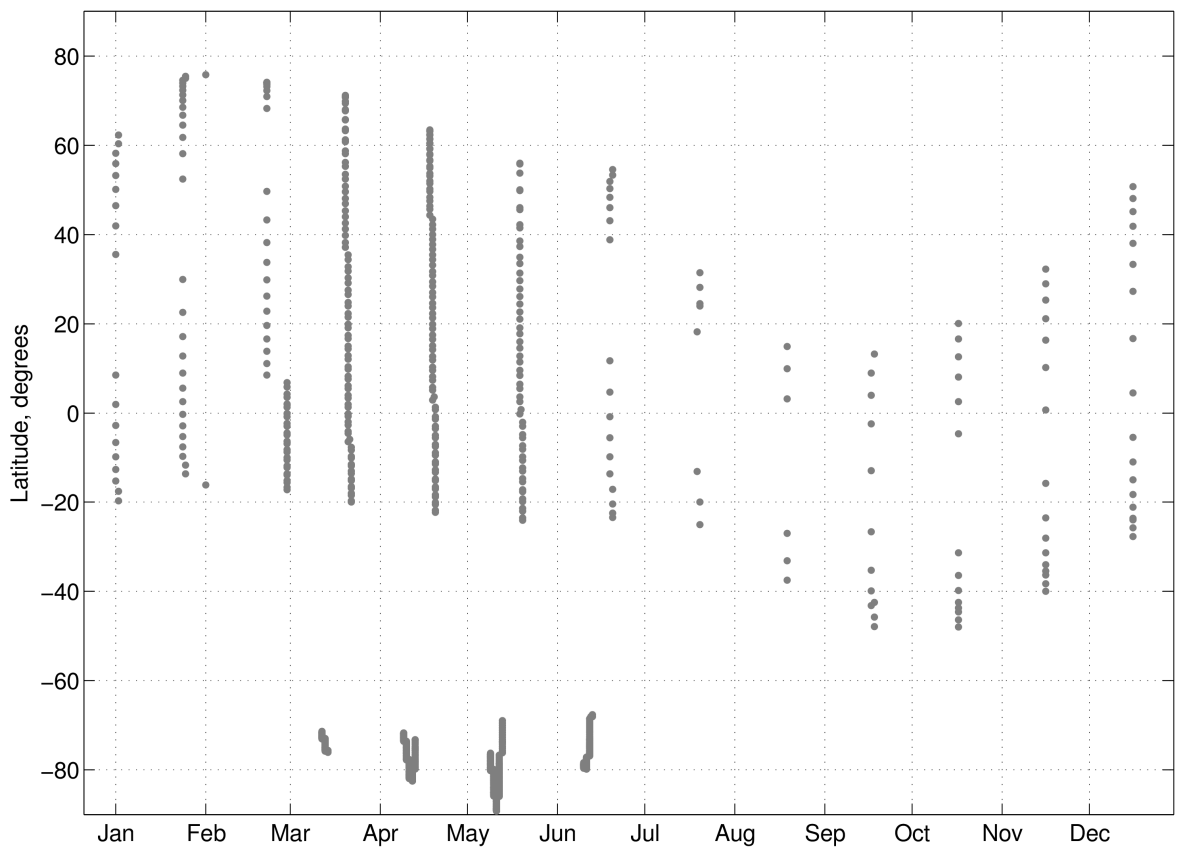

Figure 9. Annual coverage of lunar occultations. The minimal SZA at the tangent point is $102^{\circ}$, the minimal phase -0.5 . 
Atmos. Meas. Tech. Discuss., doi:10.5194/amt-2016-213, 2016

Manuscript under review for journal Atmos. Meas. Tech.

Published: 3 August 2016

(C) Author(s) 2016. CC-BY 3.0 License.

(c) (i)

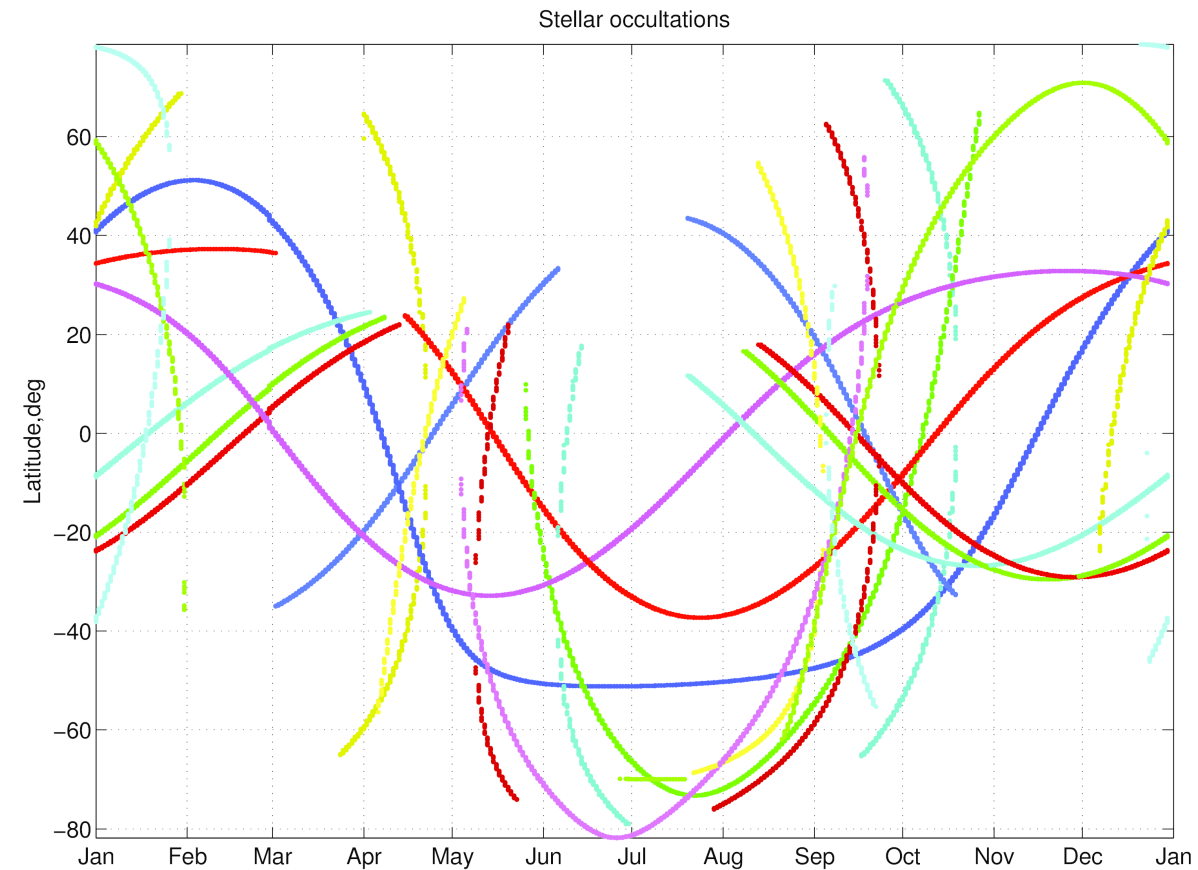

Figure 10. Annual coverage of bright stars. Stellar magnitudes are less than 1 , the minimal SZA at the tangent point is $102^{\circ}$.

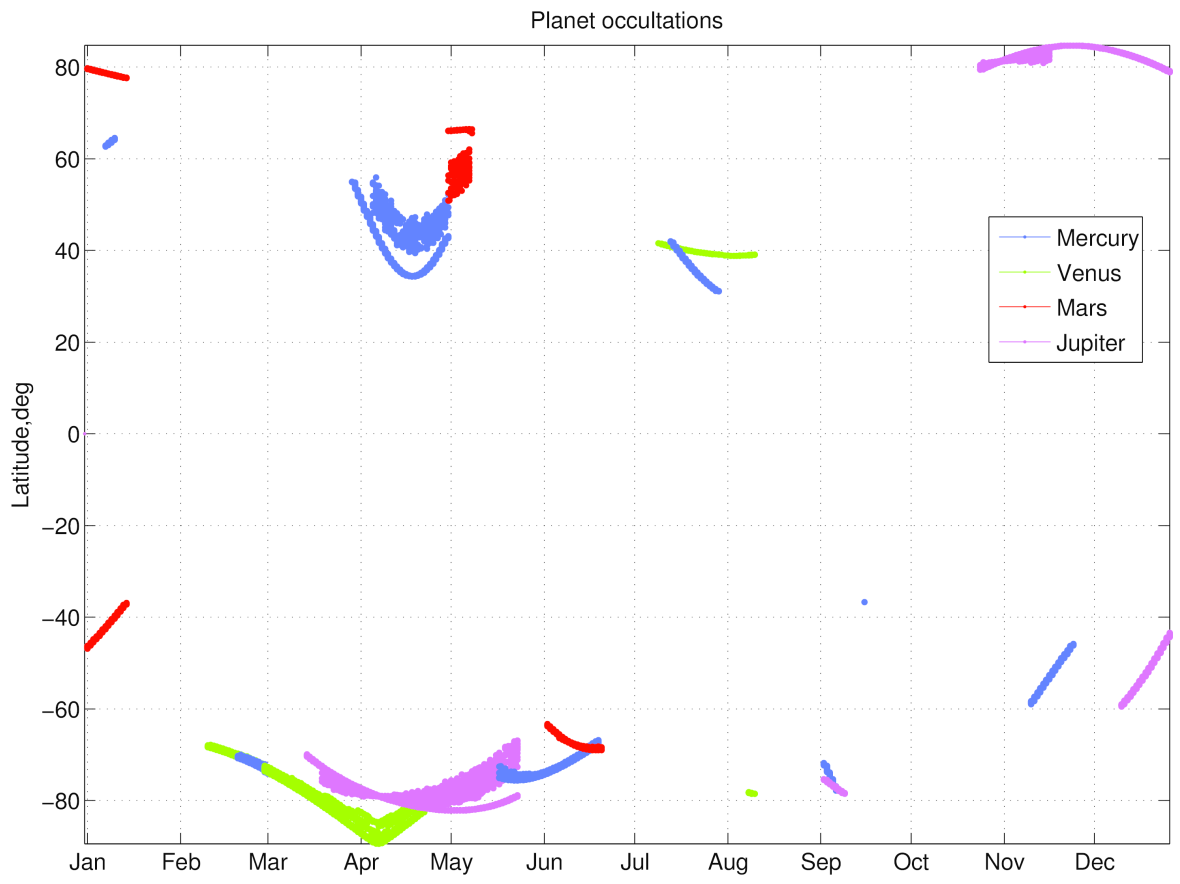

Figure 11. Annual coverage of planets. Magnitudes are less than 3 , the minimal SZA in the tangent point is $96^{\circ}$. 
Atmos. Meas. Tech. Discuss., doi:10.5194/amt-2016-213, 2016

Manuscript under review for journal Atmos. Meas. Tech.

Published: 3 August 2016

(c) Author(s) 2016. CC-BY 3.0 License.

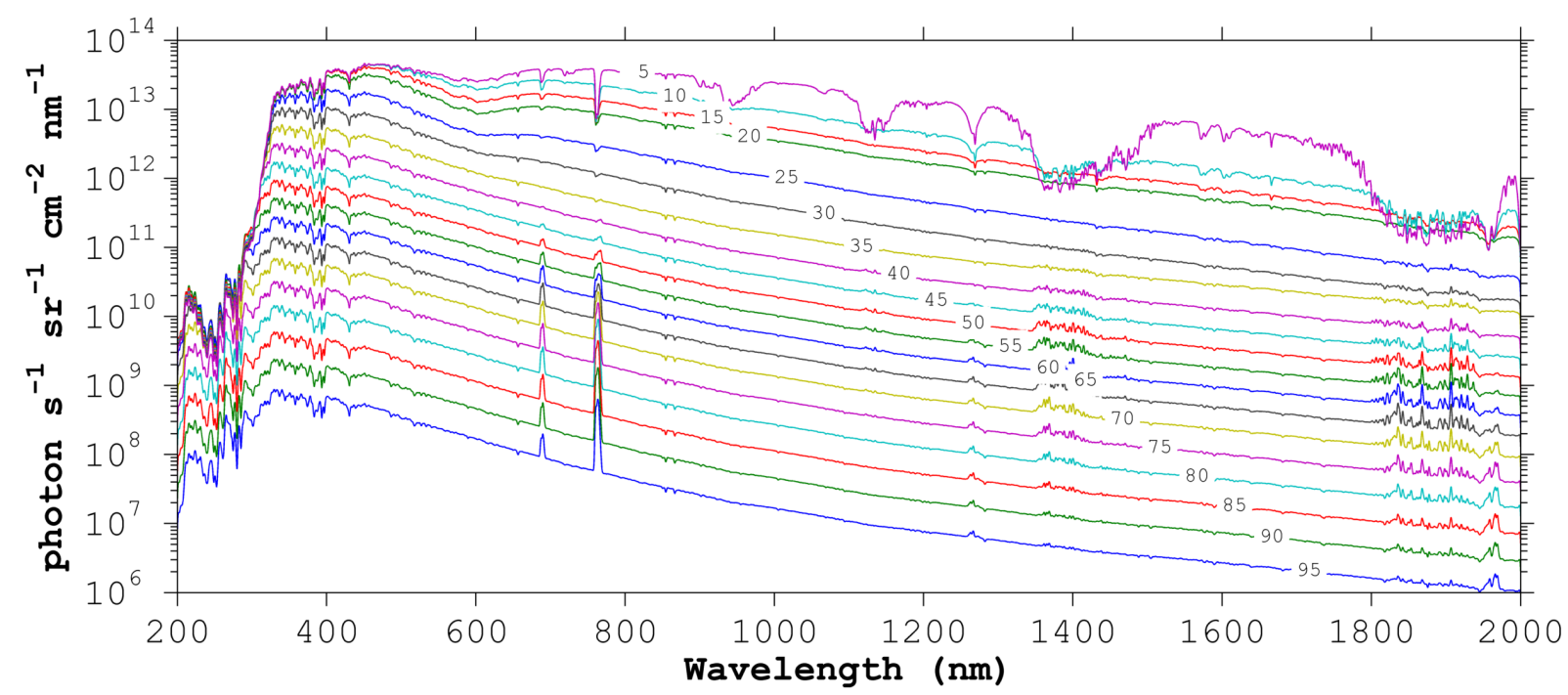

Figure 12. Limb-scattered spectral radiance as a function of tangent altitude (see curve label in $\mathrm{km}$ ) and wavelength. Simulated with MODTRAN 5 with the US standard 1976 mid-latitude summer atmospheric model at 10:30 AM local time.
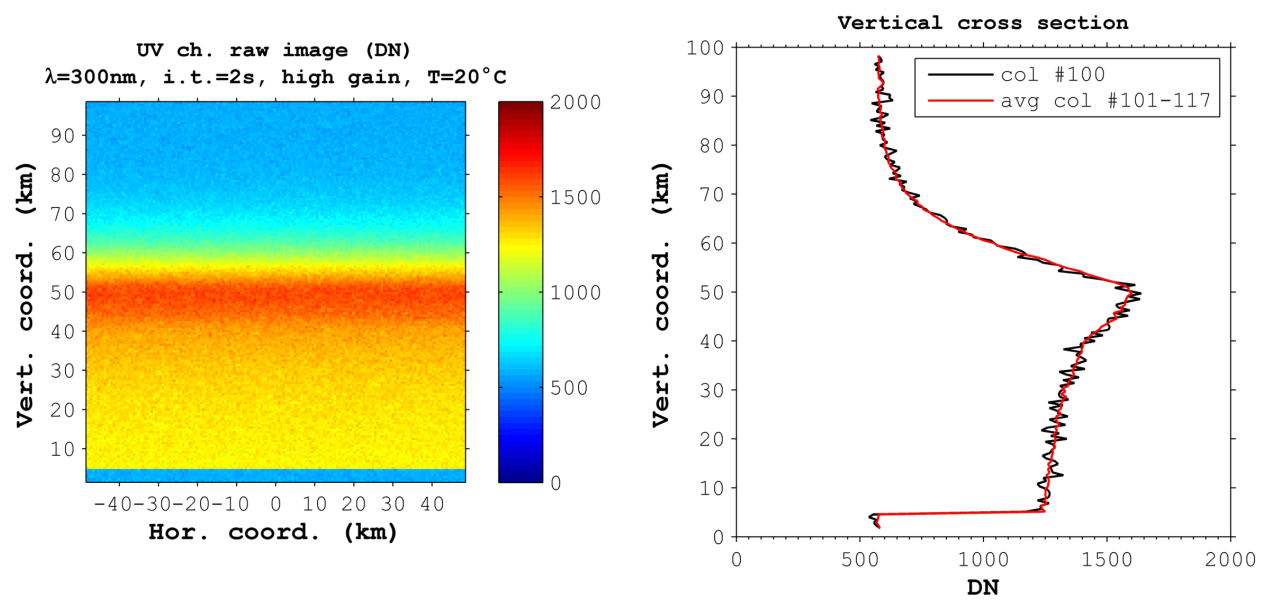

Figure 13. Left: simulated raw image acquired by the UV channel at the central wavelength of $300 \mathrm{~nm}$, an exposure time of $2 \mathrm{~s}$, the sensor in high gain and at a temperature of $20^{\circ} \mathrm{C}$. X- and Y-axis are labelled according to the tangent point coordinates. The color scale shows the registered signal in digital numbers $(\mathrm{DN})$. The noticeable noise is representative of the total uncertainty on the electronics signals (containing the signal and dark current shot noises, the readout and the quantization noises). Right: vertical cross section taken in the image at column 100 (black curve), or from the averaging of columns 101-117 (red curve). The signal profile exhibits the well-known radiometric knee used by other limb-scatter instruments to constrain their tangent height uncertainty. 
Atmos. Meas. Tech. Discuss., doi:10.5194/amt-2016-213, 2016

Manuscript under review for journal Atmos. Meas. Tech.

Published: 3 August 2016

(c) Author(s) 2016. CC-BY 3.0 License.
Atmospheric

Measurement

Techniques

Discussions

(c) (1)
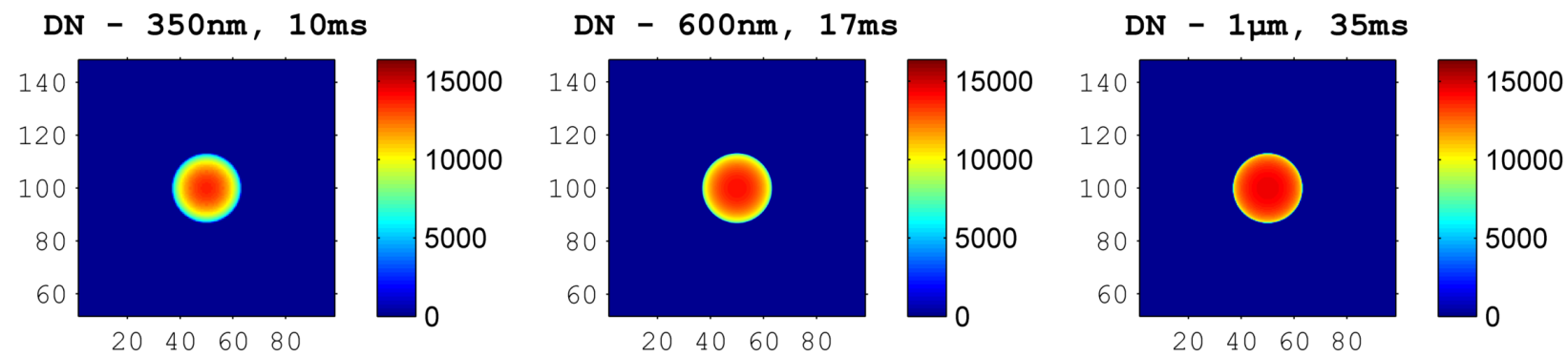

Figure 14. The three figures show the high Sun as registered by each channel at a given wavelength and exposure time (see figure labels). The color scale represents the signal registered by the pixels in digital numbers (DN). The X-and Y-axis indicate horizontal and vertical spatial coordinates (in $\mathrm{km}$ ) of the tangent point.

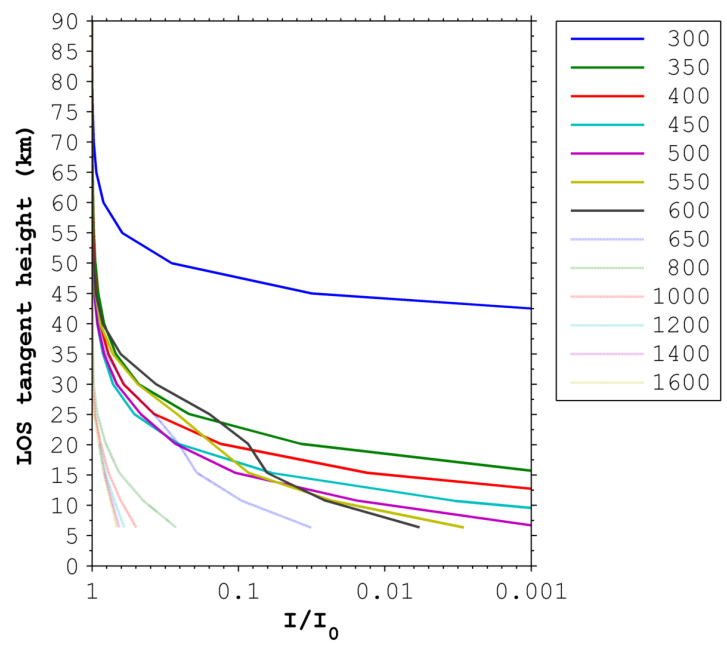

Figure 15. Transmittance of Sirius as a function of its apparent tangent altitude for several wavelengths (in nm). The extinction is caused by neutral air and aerosol scattering, $\mathrm{O}_{3}$ and $\mathrm{NO}_{2}$ absorption and refractive dilution. 
Atmos. Meas. Tech. Discuss., doi:10.5194/amt-2016-213, 2016

Manuscript under review for journal Atmos. Meas. Tech.

Published: 3 August 2016

(C) Author(s) 2016. CC-BY 3.0 License.

\section{Atmospheric Measurement \\ Techniques \\ Discussions}

(c) (i)

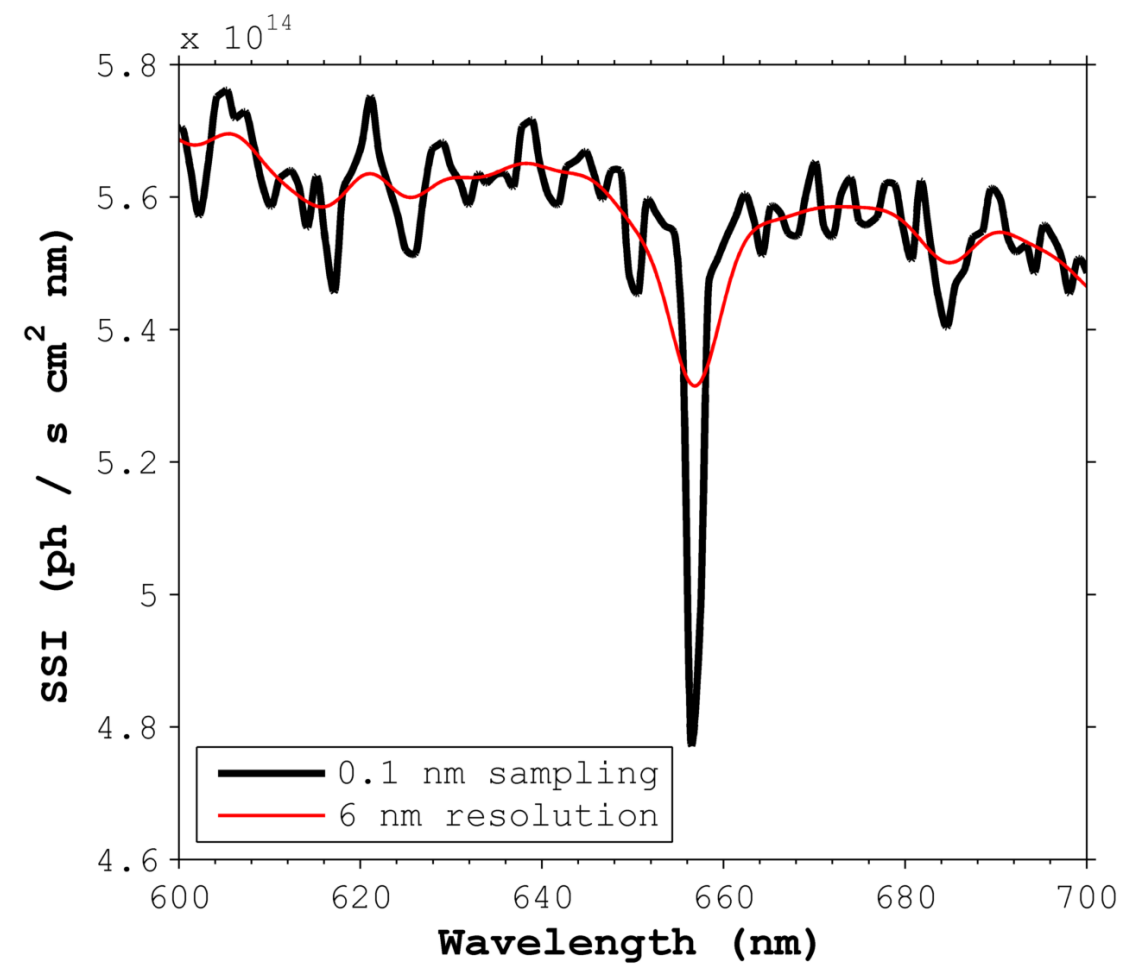

Figure 16. Solar spectral irradiance (SSI) as a function of wavelength. Data from the SOLSPEC instrument onboard ISS sampled at 0.1nm (black curve). The red curve shows the result of a sweep of the VIS channel around $655 \mathrm{~nm}$. 
Atmos. Meas. Tech. Discuss., doi:10.5194/amt-2016-213, 2016

Manuscript under review for journal Atmos. Meas. Tech.

Published: 3 August 2016

(c) Author(s) 2016. CC-BY 3.0 License.
Atmospheric

Measurement

Techniques

Discussions

(c) (1)

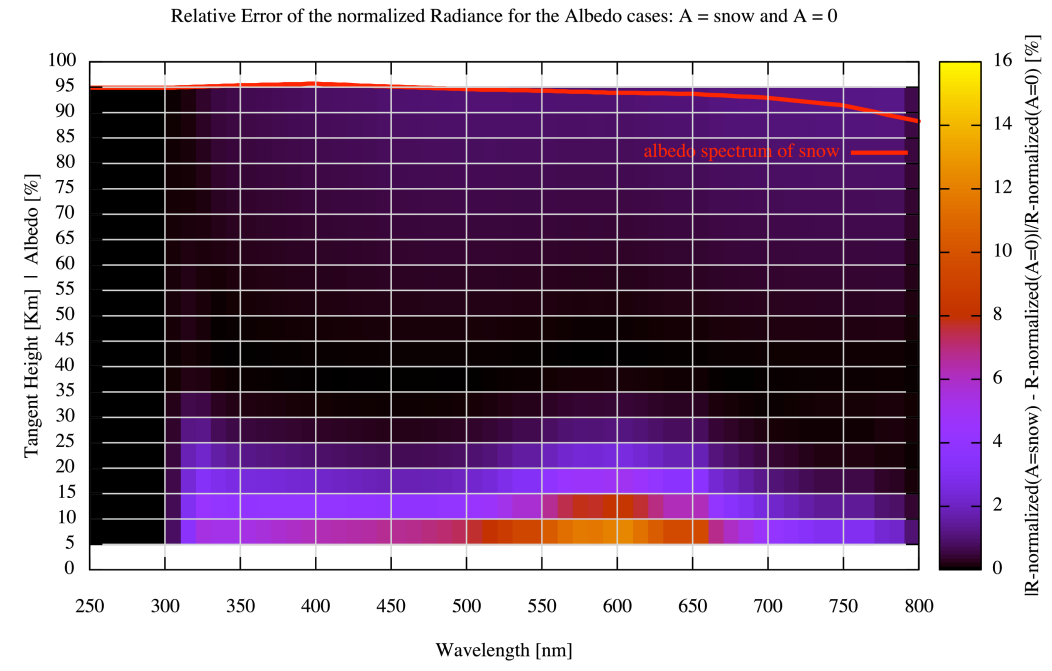

Figure 17. An upper bound of the impact of unknown albedo (through multiple scattering on renormalized radiances) can be assessed by comparing the relative difference between two extreme albedo cases $(\mathrm{A}=0$ and $\mathrm{A}=1)$ 
Atmos. Meas. Tech. Discuss., doi:10.5194/amt-2016-213, 2016

Manuscript under review for journal Atmos. Meas. Tech.

Published: 3 August 2016

(c) Author(s) 2016. CC-BY 3.0 License.

(c) (i)
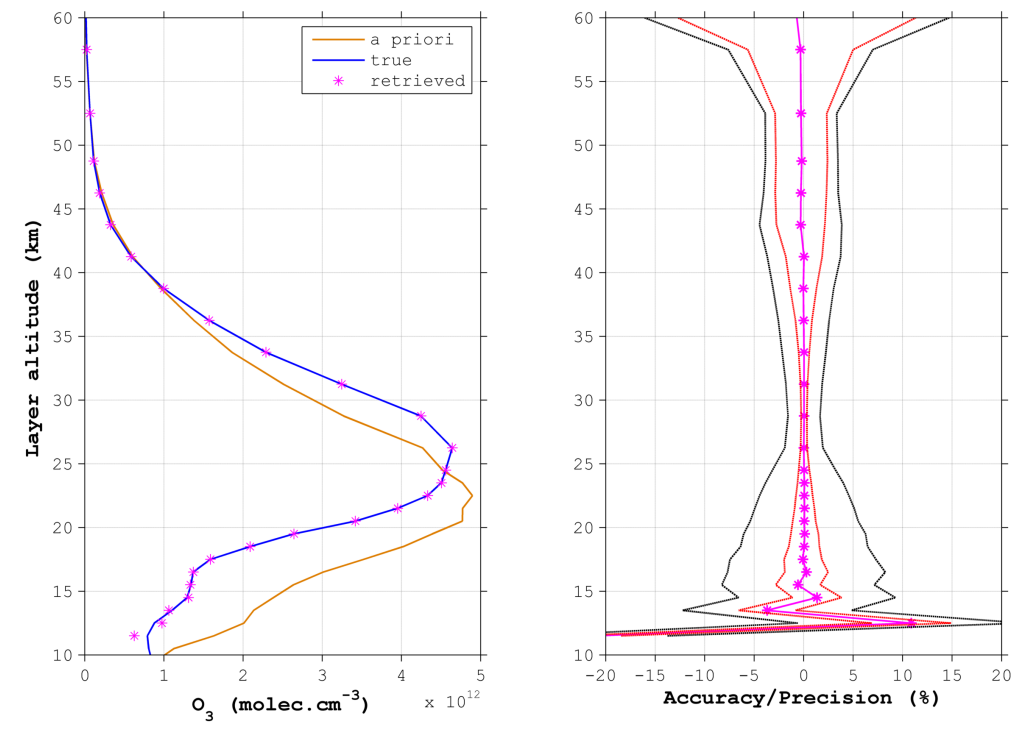

Figure 18. Left: A priori, true and retrieved ozone concentration profile. The retrieval used 3 UV and 3 VIS images of the bright limb. The true profile was taken from climatology. Right: Relative accuracy and precision of the retrieval. The pink curve is the bias between the retrieved profile and the true one. The red and black curves denotes the $\pm 1 \sigma$ interval around the solution based on the radiometric error. The black curve follows the initial SNR requirements, whereas the red curve is obtained from the latest SNR estimates.
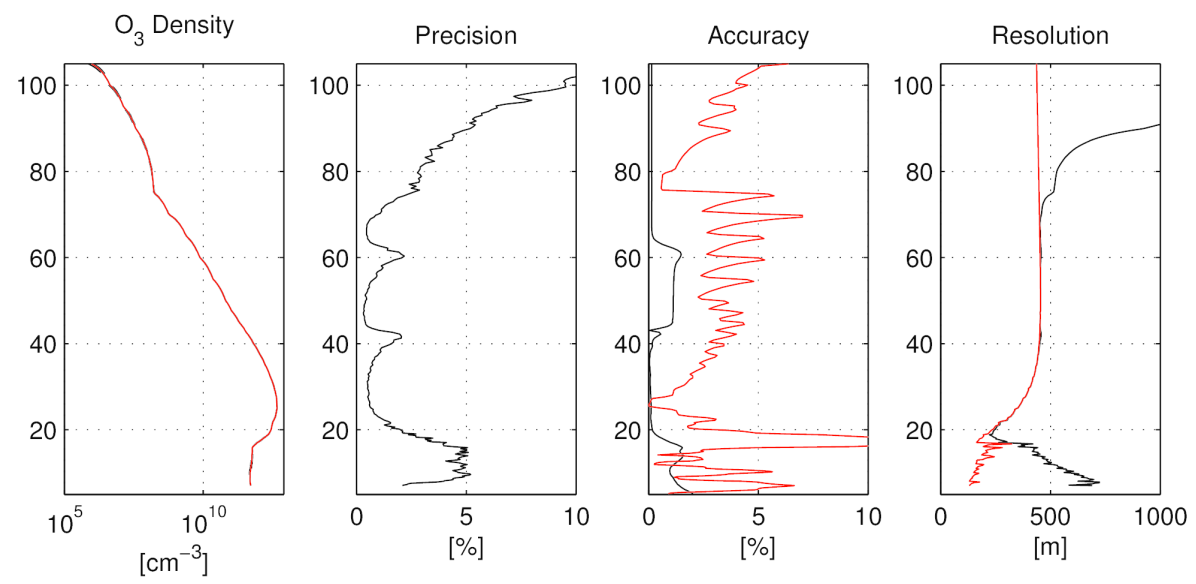

Figure 19. Solar occultation: $\mathrm{O}_{3}$ simulated retrieval results. From left to right: (1) mean and retrieval error due to detector noise (black), and true profile (red). (2) Relative standard deviation due to detector noise. (3) Bias from wavelength misregistration (black) and pointing error (red). (4) Retrieval resolution (black) and actual sampling resolution of ALTIUS. 
Atmos. Meas. Tech. Discuss., doi:10.5194/amt-2016-213, 2016

Manuscript under review for journal Atmos. Meas. Tech.

Published: 3 August 2016

(c) Author(s) 2016. CC-BY 3.0 License.

\section{Atmospheric \\ Measurement \\ Techniques \\ Discussions}

(c) (i)

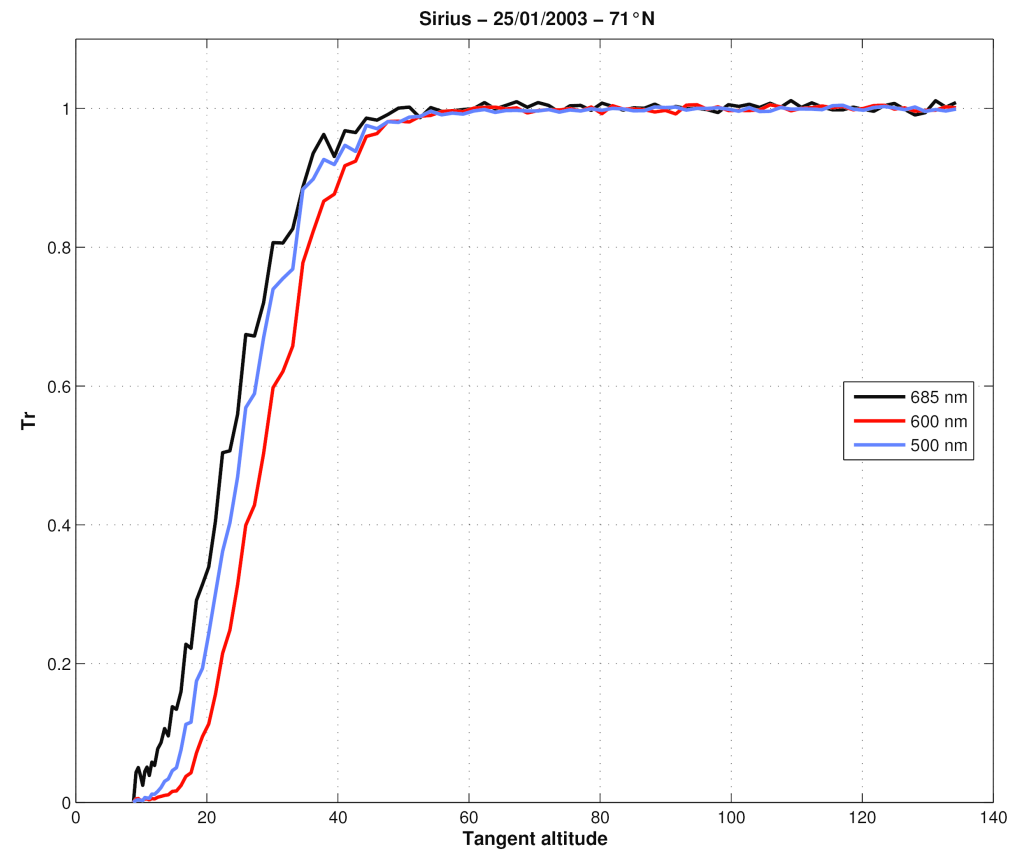

Figure 20. Transmittance of a measured Sirius occultation (by the GOMOS instrument on ENVISAT) for a triplet of wavelengths around the ozone Chappuis band

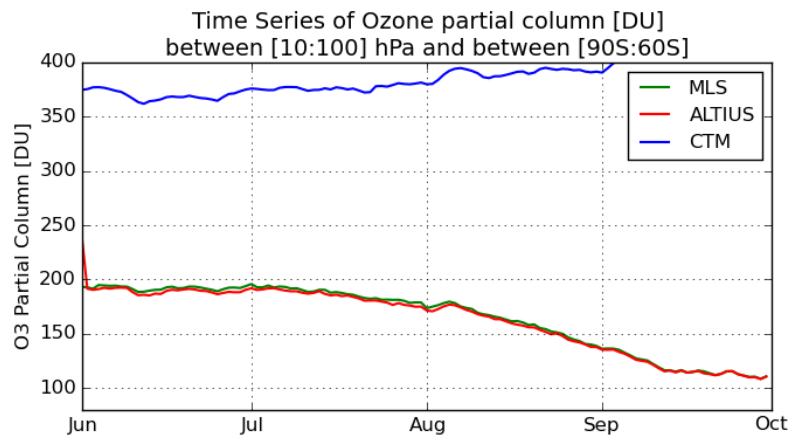

Figure 21. Time series of ozone partial column [DU] between 10 and $100 \mathrm{hPa}$ and between July and September, 2008. REAN01 stands for a synthetic ozone field derived from MLS observations, CTRL is the free BASCOE model run without assimilation and FULL stands for the assimilation of ALTIUS synthetic observations 
Atmos. Meas. Tech. Discuss., doi:10.5194/amt-2016-213, 2016

Manuscript under review for journal Atmos. Meas. Tech.

Published: 3 August 2016

(c) Author(s) 2016. CC-BY 3.0 License.

(c) (1)
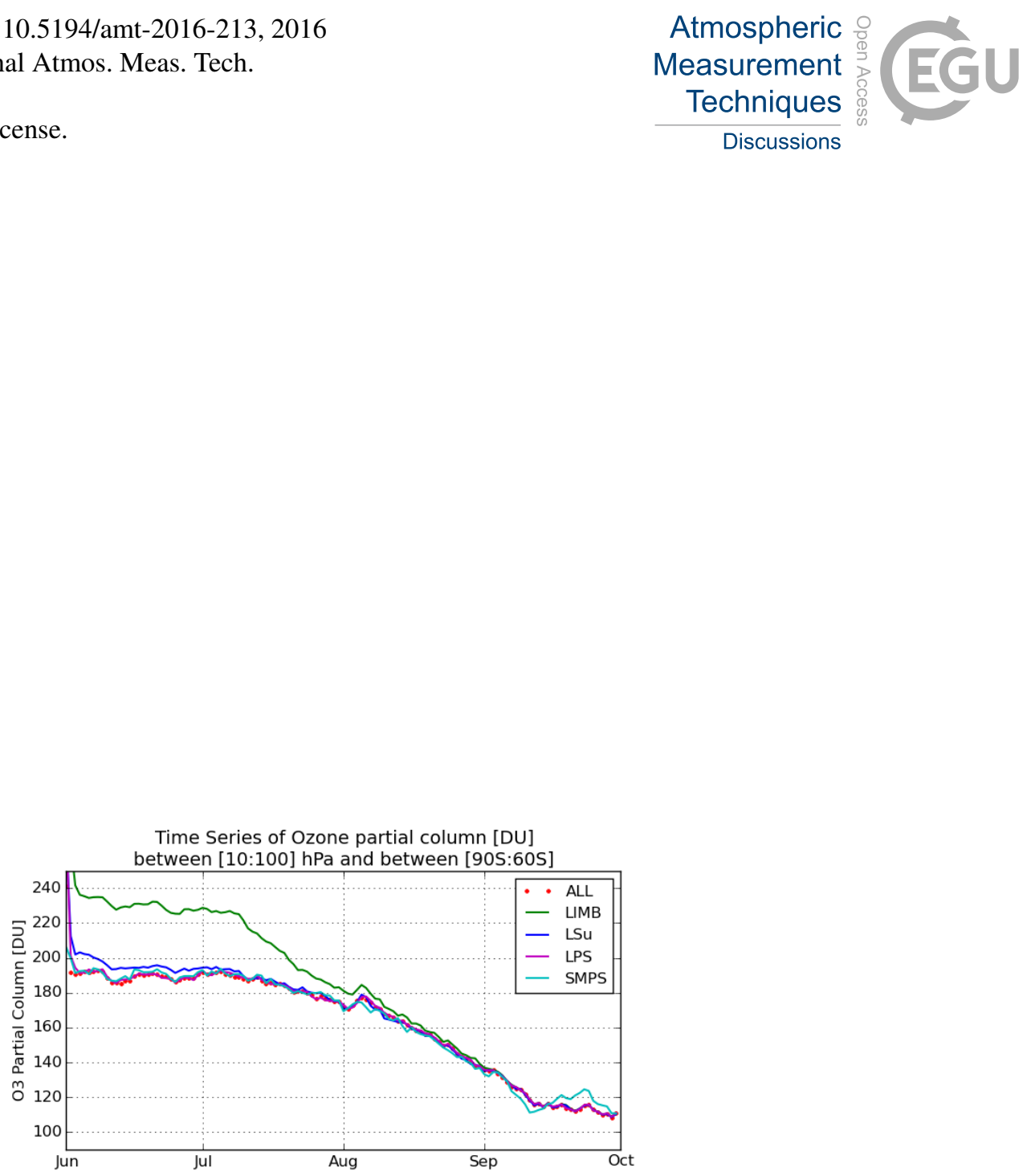

Figure 22. Impact of selective ALTIUS synthetic observations on the assimilated ozone fields (with chemistry turned off): ALL=all modes of observations are assimilated, LIMB=only limb mode assimilated, LSu=only limb and solar occultations, LPS= only limb, planet and stellar occultations assimilated, SMPS=only solar, moon, planet and stellar occultations assimilated: notice the degradation starting in Sep due to the lack of limb observations. 
Atmos. Meas. Tech. Discuss., doi:10.5194/amt-2016-213, 2016

Manuscript under review for journal Atmos. Meas. Tech.

Published: 3 August 2016

(c) Author(s) 2016. CC-BY 3.0 License.
Atmospheric Measurement Techniques

Discussions (c) (1)

\begin{tabular}{|c|c|c|c|c|c|}
\hline $\begin{array}{l}\text { Scientific } \\
\text { objectives }\end{array}$ & $\begin{array}{l}\text { Altitude } \\
\text { range }[\mathrm{km}]\end{array}$ & $\begin{array}{l}\text { Vertical } \\
\text { resolution }[\mathrm{km}]\end{array}$ & $\begin{array}{l}\text { Horizontal } \\
\text { resolution }[\mathrm{km}]\end{array}$ & $\begin{array}{l}\text { Total error }[\%] \\
\text { (Target/Threshold) }\end{array}$ & $\begin{array}{l}\text { Coverage } \\
\text { (revisit time) }\end{array}$ \\
\hline $\mathrm{SR} 1\left[\mathrm{O}_{3}\right]$ & $15-45$ & 0.5 & 50 & $5 / 20$ & Global (3 days) \\
\hline $\mathrm{SR} 2\left[\mathrm{O}_{3}\right]$ & $20-45$ & 0.5 & 50 & $3 / 10$ & Global (3 days) \\
\hline $\mathrm{SR} 3\left[\mathrm{O}_{3}\right]$ & $15-45$ & 1 & 20 & $10 / 30$ & Polar (3 days) \\
\hline $\mathrm{SR} 4\left[\mathrm{O}_{3}\right]$ & $60-100$ & 1 & 50 & $10 / 20$ & Global (3 days) \\
\hline $\mathrm{SR} 5\left[\mathrm{NO}_{2}\right]$ & $20-45$ & 1 & 25 & $15 / 40$ & Global (3 days) \\
\hline SR6.1 $\left[\mathrm{H}_{2} \mathrm{O}\right]$ & $15-30$ & 1 & 25 & $5 / 20$ & Global (3 days) \\
\hline SR6.2 $\left[\mathrm{CH}_{4}\right]$ & $15-45$ & 1 & 50 & $2 / 5$ & Global (3 days) \\
\hline SR7 [Aer] & $15-35$ & 1 & 10 & $10 / 100$ & Global (1-3 days) \\
\hline SR8 [PSC] & $10-25$ & 0.5 & 10 & $30 / 100$ & Polar (1-3 days) \\
\hline SR9 [PMC] & $75-90$ & 0.5 & 10 & $30 / 100$ & Polar (1-3 days) \\
\hline SR10.1 [OClO] & $15-50$ & 2 & 50 & $20 / 50$ & Global (3 days) \\
\hline SR10.2 [BrO] & $10-30$ & 2 & 50 & $5 / 10$ & Global (3 days ) \\
\hline $\mathrm{SR} 10.3\left[\mathrm{NO}_{3}\right]$ & $20-45$ & 1 & 25 & $15 / 40$ & Global (3 days) \\
\hline $\mathrm{SR} 11[\mathrm{~T}]$ & $15-100$ & 2 & 20 & $0.5 / 2$ & Global (3 days) \\
\hline $\mathrm{SR} 12[\nabla \mathrm{n}]$ & $15-45$ & 1 & 2 & $5 / 50$ & Polar (1-3 days) \\
\hline
\end{tabular}

Table 1. Table of ALTIUS scientific product requirements 
Atmos. Meas. Tech. Discuss., doi:10.5194/amt-2016-213, 2016

Manuscript under review for journal Atmos. Meas. Tech.

Published: 3 August 2016

(C) Author(s) 2016. CC-BY 3.0 License.
Atmospheric

Measurement

Techniques

Discussions

(c) (1)

\begin{tabular}{|c|c|c|c|}
\hline FOV & $100 \mathrm{~km} \mathrm{x} 100 \mathrm{~km}$ & IFOV & $200 \mu \operatorname{rad}(0.6 \mathrm{~km})$ \\
\hline POINTING & AXES & REQUIREMENT [mrad] & TIMESCALE [s] \\
\hline MPE & $\mathrm{R}_{Y}, \mathrm{R}_{X}, \mathrm{R}_{Z}$ & $<2,<2,<2.5$ & 1 \\
\hline MKE & $\mathrm{R}_{Y}, \mathrm{R}_{X}, \mathrm{R}_{Z}$ & $<0.1,<1,<2.5$ & 1 \\
\hline RPE & $\mathrm{R}_{Y}, \mathrm{R}_{X}, \mathrm{R}_{Z}$ & $<0.1,<1,<2.5$ & 1 \\
\hline RKE & $\mathrm{R}_{Y}, \mathrm{R}_{X}, \mathrm{R}_{Z}$ & $<0.1,<1,<2.5$ & 1 \\
\hline PDE & $\mathrm{R}_{Y}, \mathrm{R}_{X}, \mathrm{R}_{Z}$ & $<0.1,<1,<0.25$ & 10 \\
\hline $\mathrm{KDE}$ & $\mathrm{R}_{Y}, \mathrm{R}_{X}, \mathrm{R}_{Z}$ & $<0.1,<1,<0.25$ & 10 \\
\hline LIMB SCATTERING & AVERAGE NUMBER & TYPICAL DURATION & \\
\hline observations/orbit & 50 & 10 s/observation & \\
\hline images/channel/observation & 4 & 1 s/image & \\
\hline total images/orbit & 600 & & \\
\hline $\begin{array}{l}\text { STELLAR OCCULTA- } \\
\text { TIONS }\end{array}$ & AVERAGE NUMBER & TYPICAL DURATION & \\
\hline occultations/orbit & 10 & $125 \mathrm{~s}$ & \\
\hline observations/occultation & 25 & 5 s/observation & \\
\hline images/channel/observation & 4 & $0.5 \mathrm{~s} / \mathrm{image}$ & \\
\hline total images/orbit & 3000 & & \\
\hline SOLAR OCCULTATIONS & AVERAGE NUMBER & TYPICAL DURATION & \\
\hline occultations/orbit & 2 & $125 \mathrm{~s}$ & \\
\hline observations/occultation & 125 & 1 s/observation & \\
\hline images/channel/observation & 4 & $0.1 \mathrm{~s} /$ image & \\
\hline total images/orbit & 3000 & & \\
\hline
\end{tabular}

Table 2. Summary of instrument pointing and operational requirements 
Atmos. Meas. Tech. Discuss., doi:10.5194/amt-2016-213, 2016

Manuscript under review for journal Atmos. Meas. Tech.

Published: 3 August 2016

(C) Author(s) 2016. CC-BY 3.0 License.
Atmospheric

Measurement

Techniques

Discussions

\begin{tabular}{|c|c|c|c|c|c|c|c|}
\hline Species & Region & $\begin{array}{l}\text { Spectral } \\
\text { range }(\mathrm{nm})\end{array}$ & $\begin{array}{l}\text { Spectral } \\
\text { width (nm) }\end{array}$ & Limb & Stellar Occ. & Solar Occ. & $\begin{array}{l}\text { Minimal } \\
\text { SNR }\end{array}$ \\
\hline $\mathrm{O}_{3}$ & UT-LS & $550-650$ & 10 & $\mathrm{x}$ & $\mathrm{x}$ & $\mathrm{x}$ & $>200$ \\
\hline $\mathrm{O}_{3}$ & US & $300-330$ & 3 & $\mathrm{x}$ & $\mathrm{x}$ & $\mathrm{x}$ & $>70$ \\
\hline $\mathrm{O}_{3}$ & US & $550-650$ & 10 & $\mathrm{x}$ & $\mathrm{x}$ & $\mathrm{x}$ & $>50$ \\
\hline $\mathrm{O}_{3}$ & MS & $250-300$ & 3 & & $\mathrm{x}$ & $\mathrm{x}$ & $>20$ \\
\hline $\mathrm{O}_{3}$ & MS & $1260-1280$ & 3 & $\mathrm{x}$ & & & $>10$ \\
\hline $\mathrm{NO}_{2}$ & LS-US & $440-470$ & 2 & $\mathrm{x}$ & $\mathrm{x}$ & $\mathrm{x}$ & $>1500$ \\
\hline $\mathrm{H}_{2} \mathrm{O}$ & UT-LS & $900-1800$ & 5 & $\mathrm{x}$ & $\mathrm{x}$ & $\mathrm{x}$ & $>500$ \\
\hline $\mathrm{CH}_{4}$ & UT-LS & $1600-1800$ & 5 & $\mathrm{x}$ & $\mathrm{x}$ & $\mathrm{x}$ & $>500$ \\
\hline $\begin{array}{l}\text { aerosol / } \\
\text { PSC }\end{array}$ & UT-LS & $250-1800$ & 10 & $\mathrm{x}$ & $\mathrm{x}$ & $\mathrm{x}$ & $>200$ \\
\hline PMC & MS & $250-1800$ & 10 & & $\mathrm{x}$ & & $>20$ \\
\hline $\mathrm{OClO}$ & UT-US & $320-400$ & 2 & & $\mathrm{x}$ & $\mathrm{x}$ & $>100$ \\
\hline $\mathrm{BrO}$ & UT-LS & $320-360$ & 2 & $\mathrm{x}$ & $\mathrm{x}$ & $\mathrm{x}$ & $>500$ \\
\hline $\mathrm{NO}_{3}$ & LS-US & 662 & 5 & & $\mathrm{x}$ & & $>50$ \\
\hline $\mathrm{T}$ & UT-MS & Visible & 50 & & & $\mathrm{x}$ & $>1000$ \\
\hline$[\nabla \mathrm{n}]$ & UT-LS & Visible & 10 & $\mathrm{x}$ & & & $>50$ \\
\hline
\end{tabular}

Table 3. Table of ALTIUS spectral windows and target species. Atmospheric domains: UT=Upper Troposphere, LS=Lower Stratosphere US=Upper Stratosphere MS=Mesosphere

\begin{tabular}{|l|l|}
\hline Wavelengths $(\mathrm{nm})$ & $250,275,300,350,400,500,600,750,1000,1400,1800$ \\
\hline Tangent heights $(\mathrm{km})$ & $0,2.5,5,7.5,10,15,20,25,30,40,50,60,75,100$ \\
\hline Solar zenith angles (deg.) & $0,15,30,45,60,75,90$ \\
\hline View zenith angles (deg.) & $0,15,30,45,60,75,90,105,120,135,150,165,180$ \\
\hline Relative azimuth angles (deg.) & $0,30,60,90,120,150,180$ \\
\hline Albedo & $0.0,0.3,0.6,0.9$ \\
\hline
\end{tabular}

Table 4. Stokes vector look-up tables 
Atmos. Meas. Tech. Discuss., doi:10.5194/amt-2016-213, 2016

Manuscript under review for journal Atmos. Meas. Tech.

Published: 3 August 2016

(C) Author(s) 2016. CC-BY 3.0 License.
Atmospheric

Measurement

Techniques

Discussions

\begin{tabular}{|l|l|l|l|l|l|l|}
\hline & Molecule & $\begin{array}{l}\text { Vertical } \\
\text { Region }\end{array}$ & $\begin{array}{l}\text { Target } \\
\text { Threshold } \\
\text { Tot. Error (\%) }\end{array}$ & BL & SoO & StO \\
\hline SR1 & $\mathrm{O}_{3}$ & UT/LS & $5 / 20$ & 3 & 3 & 3 \\
\hline SR2 & $\mathrm{O}_{3}$ & US & $3 / 10$ & 3 & 3 & 2 \\
\hline SR3 & $\mathrm{O}_{3}$ & UT/LS polar & $10 / 30$ & N/A & 3 & 2 \\
\hline SR4 & $\mathrm{O}_{3}$ & MS & $10 / 20$ & N/A & 3 & 2 \\
\hline SR5 & $\mathrm{NO}_{2}$ & Strato & $15 / 40$ & 2 & 3 & 2 \\
\hline SR6.1 & $\mathrm{H}_{2} \mathrm{O}$ & UT/LS & $5 / 20$ & 1 & 2 & 2 \\
\hline SR6.2 & $\mathrm{CH}_{4}$ & UT/LS & $2 / 5$ & 1 & 2 & 2 \\
\hline SR7 & $\mathrm{Aerosol}$ & UT/LS & $10 / 100$ & 3 & 3 & 2 \\
\hline SR8 & $\mathrm{PSC}_{\mathrm{SR} 9}$ & $\mathrm{UT} / \mathrm{LS}$ & $30 / 100$ & 3 & 3 & 3 \\
\hline SRC & MS & $30 / 100$ & 3 & 2 & N/A \\
\hline SR10.1 & $\mathrm{OClO}$ & Strato & $20 / 50$ & N/A & 1 & 1 \\
\hline SR10.3 & $\mathrm{BrO}$ & UT/LS & $5 / 10$ & 1 & 1 & N/A \\
\hline SR11 & $\mathrm{NO}_{3}$ & UT/LS night & $15 / 40$ & N/A & 1 & 1 \\
\hline SR12 & $\mathrm{T}$ & UT-MS & $0.5 / 2(\mathrm{~K})$ & N/A & 1 & N/A \\
\hline
\end{tabular}

Table 5. ALTIUS performance levels obtained so far for bright limb (BL), solar (SoO)and stellar (StO) occultations observation modes. "3"="target met or proven by design", "2"="threshold met", "1"="not studied yet or require further studies"

\begin{tabular}{|l|l|l|l|l|l|l|l|l|l|l|}
\hline $\begin{array}{l}\text { Error } \\
\text { source }\end{array}$ & $\begin{array}{l}\text { Error } \\
\text { Type }\end{array}$ & $15 \mathrm{~km}$ & $20 \mathrm{~km}$ & $25 \mathrm{~km}$ & $30 \mathrm{~km}$ & $35 \mathrm{~km}$ & $40 \mathrm{~km}$ & $45 \mathrm{~km}$ & $50 \mathrm{~km}$ & $55 \mathrm{~km}$ \\
\hline SNR & random & $7 \%(2)$ & $6 \%(1)$ & $2.5 \%(1)$ & $2 \%(1)$ & $2 \%(1)$ & $3 \%(2)$ & $4 \%(3)$ & $4 \%(3)$ & $6 \%(4)$ \\
\hline Pointing & bias & $5.00 \%$ & $5.00 \%$ & $1.00 \%$ & $2.00 \%$ & $2.00 \%$ & $3.00 \%$ & $4.00 \%$ & $3.00 \%$ & $4.00 \%$ \\
\hline Spectral & bias & $0.00 \%$ & $0.00 \%$ & $0.00 \%$ & $0.00 \%$ & $0.00 \%$ & $0.50 \%$ & $1.00 \%$ & $1.00 \%$ & $1.00 \%$ \\
\hline Total & $8.6 \%$ & $7.8 \%$ & $2.7 \%$ & $2.8 \%$ & $2.8 \%$ & $4.3 \%$ & $5.7 \%$ & $5.1 \%$ & $7.3 \%$ & $(5.7)$ \\
& $(5.4)$ & $(5.1)$ & $(1.4)$ & $(2.2)$ & $(2.2)$ & $(3.7)$ & $(5.1)$ & $(4.4)$ & ( & \\
\hline
\end{tabular}

Table 6. Limb scattering $\mathrm{O}_{3}$ error budget. The total error is the RSS of the three error components. The numbers in parenthesis are obtained if the expected L1 performance is considered. 